1 Aspartyl Protease 5 matures virulence factors found at the host-parasite interface in

\title{
2 Toxoplasma gondii
}

6 Michael J Coffey ${ }^{1,2}$, Laura F Dagley ${ }^{1,2}$, Eugene A Kapp ${ }^{1,2}$, Giuseppe Infusini ${ }^{1,2}$, Justin A

7 Boddey $^{1,2}$, Andrew I Webb ${ }^{1,2}$ and Christopher J Tonkin ${ }^{1,2^{*}}$.

$10{ }^{1}$ - The Walter and Eliza Hall Institute of Medical Research, Melbourne, Australia

$11^{2}$ - The Department of Medical Biology, The University of Melbourne, Melbourne, Australia

15 *For Correspondence:

16 Chris Tonkin

17 Division of Infection and Immunity

18 The Walter and Eliza Hall Institute of Medical Research

19 1G Royal Parade, Parkville 3052, Victoria, Australia

$20 \mathrm{Ph}:+61393452926$

21 Fax: +61393470852

22 Email: tonkin@wehi.edu.au 


\section{Abstract}

25 Toxoplasma gondii infects approximately $30 \%$ of the world's population, causing disease

26 primarily during pregnancy and in individuals with weakened immune systems. Toxoplasma

27 secretes and exports effector proteins that modulate the host during infection and several of these

28 proteins are processed by the Golgi-associated Aspartyl Protease 5 (ASP5). Here, we identify

29 ASP5 substrates by selectively enriching N-terminally-derived peptides from wildtype and

$30 \Delta a s p 5$ parasites. We reveal over two thousand unique Toxoplasma $\mathrm{N}$-terminal peptides, mapping

31 to both natural N-termini and protease cleavage sites. Several of these peptides mapped directly

32 downstream of the characterised ASP5-cleavage site, arginine-arginine-leucine (RRL). We

33 validate candidates as true ASP5 substrates, revealing they are not processed in parasites lacking

34 ASP5, nor in wild type parasites following mutation of the motif from RRL $\rightarrow$ ARL. All new

35 ASP5 substrates are dense granule proteins, and interestingly none appear to be exported, thus

36 differing from the analogous system in related Plasmodium spp., instead revealing that the

37 majority of substrates reside within the parasitophorous vacuole (PV), and its membrane (the

38 PVM), including two kinases and one phosphatase. Furthermore, we show that several of these

39 ASP5-substrates are virulence factors, with their removal leading to attenuation in a mouse

40 model, suggesting that phosphorylation at the host-parasite interface is important for virulence.

41 Collectively, these data constitute the first in-depth analyses of the total list of ASP5 substrates,

42 and shed new light on the role of ASP5 as a maturase of dense granule proteins during the

43 Toxoplasma lytic cycle. 


\section{Importance}

45 Toxoplasma gondii is one of the most successful human parasites. Central to its success is the

46 arsenal of virulence proteins introduced into the infected host cell. Several of these require direct

47 maturation by the aspartyl protease ASP5, and all require ASP5 for translocation into the host

48 cell, yet the true number of ASP5 substrates is currently unknown. Here we selectively enrich N-

49 terminally-derived peptides using Terminal Amine Isotopic labelling of Substrates (TAILS) and

50 quantitative proteomics to reveal novel ASP5 substrates. We identify, using two different

51 enrichment techniques, new ASP5 substrates and their specific cleavage sites. ASP5 substrates

52 include two kinases and one phosphatase that reside at the host-parasite interface, which are

53 important for infection. 


\section{Introduction}

55 Apicomplexan parasites are the causative agents of many diseases of important medical and

56 agricultural significance. As obligate intracellular pathogens, these parasites must invade and

57 then survive within the infected host cell whilst obtaining nutrients in order to replicate.

58 Toxoplasma gondii is the most widespread and successful of all apicomplexan parasites, and

59 resides in nucleated cells of nearly all warm-blooded organisms, including birds and mammals.

60 Initial infection in immunocompetent humans is generally mild, however some highly virulent

61 South American strains of Toxoplasma exist and cause progressive blindness in otherwise

62 healthy individuals (1). Further, reactivation of latent infection within immunocompromised

63 populations, such as AIDS and immunotherapy patients, can cause severe disease and death (2).

65 Central to the success of Toxoplasma is its ability to modulate the host response, a process

66 achieved through the secretion and export of an arsenal of effector proteins. Subversion of the

67 host enables the parasites to survive and proliferate within the parasitophorous vacuole (PV), a

68 structure that delimits Toxoplasma from the hostile intracellular environment. At the molecular

69 level, Toxoplasma achieves this fine balance of immune modulation by the orchestrated secretion

70 of effector proteins using two separate protein trafficking pathways. Proteins from the rhoptry

71 organelles (termed ROPs) are introduced during the invasion process where they simultaneously

72 promote a pro-inflammatory microenvironment to protect the host from excessive parasite

73 growth, whilst also ensuring Toxoplasma is not cleared by the mounting immune response (3-

$74 \quad 11)$. 
76 More recently, it has been shown that another protein export pathway exists. Here, dense granule

77 proteins (GRAs) are secreted post-invasion and can modulate the host either by localising to the

78 PV membrane (PVM) or by translocating across this barrier and residing within the host cell.

79 GRA15, for example, localises to the host cytosolic side of the PVM where it activates the host

$80 \mathrm{NF}_{\mathrm{K}} \mathrm{B}$ pathway to induce a protective immune response against the parasite (12), whilst the

81 transmembrane protein MAF1 recruits host mitochondria to the PVM (13).

83 Another group of dense granule proteins are translocated across the PVM and into the host cell.

84 GRA16 traffics to the host cell nucleus where it interacts with the phosphatase PP2A and the

85 ubiquitin protease HAUSP, potentially interfering with the cell cycle to avoid premature immune

86 detection $(14,15)$. GRA24, on the other hand, induces a protective response through the

87 prolonged activation of the MAPK protein $\mathrm{p} 38 \alpha$ leading to controlled replication within the gut

88 of infected mice $(15,16)$. One of the major subversion mechanisms of Toxoplasma is the loss of

89 the infected host cell's ability to mount an IFN $\gamma$ response. This response is circumvented by the

90 dense granule protein IST (inhibitor of STAT1-dependent transcription). IST directly binds to

91 activated STAT1 in the host nucleus and recruits a chromatin remodelling complex to block the

92 transcription of STAT1-dependent promoters $(17,18)$. GRA28 was discovered in a screen by

93 tagging a dense granule protein with the promiscuous biotin ligase BirA, although its role in the

94 host nucleus has not yet been elucidated (19).

96 The precise mechanism of how Toxoplasma proteins translocate across the PVM is currently

97 unclear; however, the export of GRA16, GRA24 and IST is dependent on the Golgi-resident

98 aspartyl protease ASP5, which is known to directly process the exported protein GRA16, and 
99 likely IST. Despite not proteolytically maturing GRA24 (17, 20-22), export of this effector still

100 requires the activity of ASP5. ASP5 cleaves its substrates at a defined motif termed the TEXEL

101 (Toxoplasma Export Element) a conserved motif consisting of RRLxx, so named as it is

102 homologous to the cleavage of the Plasmodium export element (PEXEL, commonly

$103 \mathrm{RxLxE} / \mathrm{Q} / \mathrm{D})$ by the ER-resident protease plasmepsin V (PMV) (20, 23-27). Within malaria

104 parasites, the PEXEL appears to only occur near the N-terminus of the protein and its cleavage

105 by PMV somehow licenses proteins for export across the PVM via the Plasmodium translocon of

106 exported proteins (PTEX) (24, 28-36).

108 Despite similarities, there are also several key differences between these pathways in

109 Toxoplasma and Plasmodium. ASP5 resides within the Golgi, where it cleaves the TEXEL that

110 can be found at the N- or C-terminus of the substrate. Further, while all reported PEXEL proteins

111 are exported, it appears only a subset of ASP5 substrates are translocated into the host cell. We

112 recently reported that ASP5 processes the PVM protein MYR1, a likely component of the

113 Toxoplasma translocon $(20,37)$. Further, previous work by us and others demonstrated that

114 ASP5-dependent effectors substantially alter the transcriptional profile of the host cell. Due to its

115 central role in host cell subversion, parasites lacking ASP5 exhibit decreased virulence in mice,

116 even in the normally lethal RH strain $(20,22)$.

118 Despite the importance of ASP5, only a handful of ASP5 substrates have been identified, and the

119 true number of substrates remains unknown. Indeed, identification of new ASP5 substrates could

120 identify new effector proteins and virulence factors driving the persistence of Toxoplasma. To

121 identify new ASP5-dependent effector proteins, we have 
122 utilised a quantitative proteomic pipeline in combination with the selective enrichment of $\mathrm{N}$ -

123 terminally derived peptides. These methods included Terminal Amine Isotopic Labelling of

124 Substrates (TAILS) (38) and Hydrophobic Tagging-Assisted N-Terminal Enrichment

125 (HYTANE) (39), which enabled us to compare differences in the N-terminome between

126 wildtype (WT) and $\triangle a s p 5$ tachyzoites. Enrichment of N-terminal peptides by TAILS and

127 HYTANE has enabled the identification of protease cleavage sites dependent on ASP5.

129 Moreover, we validated the N-terminal enrichment data and report that ASP5 matures several

130 new dense granule proteins that appear to be localised within the confines of the parasitophorous

131 vacuole. We present LCAT (40) and a new dense granule protein, GRA43, as ASP5 substrates

132 that are processed close to the C-terminal end of the polypeptide. Further, we validate WNG1

133 and WNG2, formerly ROP35 and ROP34, as two new dense granule protein kinases processed

134 by ASP5. This study greatly increases the number of known ASP5 substrates, including several

135 involved Toxoplasma virulence, demonstrating the important role protein maturation plays in

136 pathogenesis. 


\section{Results}

140 Identification of ASP5 substrates by N-terminal enrichment

141 In our current model, we propose that Toxoplasma effectors enter the ER via an N-terminal

142 signal peptide that is subsequently cleaved by signal peptidase. Proteolytic cleavage can result in

143 acetylation (or not) of the new N-termini (Figure 1A). Upon reaching the Golgi apparatus, ASP5

144 matures substrates at the TEXEL (RRLxx), prior to transport across the parasite plasma

145 membrane (PPM) (Figure 1A). Within the PV space, some substrates are inserted into the PVM,

146 while others are exported into the host cell. Parasites that lack ASP5 are unable to mature these

147 substrates within the Golgi, resulting in different N-termini, commonly represented as the signal

148 peptide cleavage site (Figure 1A).

150 To discover new ASP5 substrates we used three unbiased quantitative proteomics approaches

151 (SILAC, heavy dimethyl labelling and label-free quantitation) in combination with two

152 techniques to enrich N-terminally-derived peptides (TAILS and HYTANE) (Figure 1B). Both

153 techniques rely on formaldehyde-based dimethylation to block free amines on the N-termini of

154 proteins and side chains of lysine residues. Secondly, proteins are enzymatically digested with

155 trypsin, liberating internal tryptic peptides (which have 'free' non-acetylated N-termini) from N-

156 terminal peptides with blocked amines. The internal peptides are then depleted using an

157 aldehyde-derived polymer (TAILS) or hexadecanal, an amine-reactive reagent (HYTANE), thus

158 enriching for N-terminal peptides. Subsequent mass spectrometry analyses of these N-terminal

159 peptides allow for quantitative differences to be measured in an unbiased fashion thus enabling 
160 the identification of protease cleavage sites when used in combination with protease-deficient

161 genetic mutants.

163 Quantitative proteomic approaches

164 We used SILAC, differential dimethylation and label-free methodologies to quantitate N-

165 terminally-derived peptide abundance between wildtype and ASP5-deficient parasites. Prior to

166 beginning the TAILS protocol, reciprocally-labelled SILAC proteins were isolated from WT or

$167 \Delta a s p 5$ parasites and mixed in equal concentrations (Figure 1C). The SILAC-TAILS samples

168 were subjected to high $\mathrm{pH}$ fractionation to decrease sample complexity resulting in 12 total

169 fractions per SILAC pair. For Dimethyl labelling, proteins were extracted from WT or $\Delta a s p 5$

170 parasites, reciprocally-blocked with either light (normal) or deuterated (heavy) formaldehyde,

171 then mixed and processed together for the remainder of the protocol (Figure 1C). All samples

172 were then desalted and subsequently run on the mass spectrometer to determine the identity of

173 peptides. Relative peptide quantification with heavy dimethylation and SILAC-based strategies

174 were performed in MS1 mode whilst area-under-the-curve measurements were performed for

175 label-free quantitation. The N-termini in the SILAC and heavy dimethyl experiments were

176 enriched using the TAILS method whilst the HYTANE method was used for the label-free

177 quantitative proteomics experiments (Figure 1C).

179 First, we verified N-terminal enrichment using the HPG-ALD synthetic polymer previously

180 developed for the TAILS protocol (38) (Figure 2A). In pre-TAILS SILAC samples, we found

181 that only $\sim 9 \%$ of all identified Toxoplasma peptides matched to N-terminally blocked peptides.

182 However, upon TAILS enrichment the blocked peptides consisted of $\sim 70 \%$ of the sample, 
183 reflecting a 7-fold N-terminal enrichment. The bulk of these modified peptides were

184 experimentally dimethylated or naturally acetylated. Overall, we identified 2246 N-terminal

185 peptides across the three experiments with the majority identified in the SILAC-TAILS (1505

186 peptides) followed by the HYTANE strategy (916 peptides) and heavy dimethylation-TAILS

187 (327). The majority of modified peptides in the HYTANE and dimethylation-TAILS

188 experiments were acetylated representing natural $\mathrm{N}$-termini whilst the majority of peptides in the

189 SILAC-TAILS were experimentally dimethylated (Figure 2B). TAILS should deplete tryptic

190 peptides indiscriminately, and therefore it is not understood why there is variation in the identity

191 of blocked peptides between these depletion methods. Using an alternative method for N-termini

192 enrichment (HYTANE), we identified a substantial improvement in the number of modified N-

193 termini with less than $15 \%$ being unmodified (Figure 2C). Comparison of the data sets revealed

19479 peptides with modified N-termini that were common to each of the three quantitative

195 proteomics experiments (Figure 2D). Collectively, SILAC-TAILS identified the majority of N-

196 terminal peptides; however, each approach revealed novel peptides that were not found in the

197 other experiments, demonstrating the importance of employing multiple N-terminome

198 methodologies.

200 We then interrogated differences in abundance of N-terminal peptides from WT and $\triangle a s p 5$

201 tachyzoites across all methodologies. Here, we found that the SILAC-based peptide quantitation

202 revealed 51 Toxoplasma peptides with modified N-termini that were significantly differentially

203 abundant between the WT and $\triangle a s p 5$ samples (Table S1), including three novel ASP5 substrates

204 - TGME49_272420 (LCAT), TGME49_208370 (GRA43) and TGME49_240090 (WNG2,

205 previously annotated as ROP34, Figure 2E). Differential dimethylation-TAILS revealed a total 
of 26 Toxoplasma peptides with modified N-termini that were significantly differentially

207 abundant between the WT and $\triangle a s p 5$ samples (Table S1), including TGME49_304740 (WNG1,

208 previously annotated as ROP35) (Figure 2F). Label-free quantitative proteomics analysis

209 revealed a number of modified peptides uniquely present in the WT samples including

210 TGME49_228170 (GRA44) and WNG2 (ROP34) (Table 1 and Table S1).

212 In total, we identified over 2000 unique N-terminal peptides across the three methodologies.

213 Many of these peptides were not significantly different between WT and $\triangle a s p 5$ parasites, having

214 arisen from natural $\mathrm{N}$-termini (both exposed and acetylated) as well as from other protease

215 cleavage events within parasites. However, each methodology also revealed unique peptides that

216 mapped directly after an RRL motif, enabling the identification of likely novel ASP5 substrates.

\section{The PVM protein LCAT is processed by ASP5}

219 We sought to validate newly identified proteins as ASP5 substrates. To do this we endogenously

220 tagged candidate proteins in both wildtype and $\Delta a s p 5$ tachyzoites, then mutated the putative

221 RRL cleavage site to look for differential processing within parasites. For tagging and

222 mutagenesis of almost all proteins, we designed Cas9-targeting guides against the gene-of-

223 interest and co-transfected these with two annealed $\sim 60$ base pair oligos to introduce either an

224 epitope tag, mutate an RRL $\rightarrow$ ARL, or disrupt the gene (Figure 3A). We first chose to investigate

225 a recently discovered dense granule protein LCAT (TGME49_272420) that is secreted to the

226 PVM, as we identified an N-terminal peptide found exclusively in WT parasites with the

227 sequence (dimethyl)-DAVLTDEVGGPESGAR (Table 1), which mapped to a location directly

228 C-terminal of an RRL sequence within this protein (40). LCAT is processed into two fragments 
229 by an unknown protease within the 'inserted element (IE)' that separates the catalytic residues of

230 the enzyme (40). As the TAILS peptide mapped to directly after an RRL within this IE, we

231 tagged endogenous LCAT and observed a $~ 90 \mathrm{kDa}$ 'full-length' species and a $40 \mathrm{kDa}$

232 processed form (Figure 3B). We then tagged LCAT in $\triangle a s p 5$ parasites and primarily observed

233 the larger molecular weight species (Figure 3B), with a doublet band at $\sim 60 \mathrm{kDa}$ that may be a

234 degradation product or result from a subsequent processing event. To confirm that the loss of the

$235 \sim 40 \mathrm{kDa}$ species was mediated by ASP5, we then swapped the endogenous RRL to ARL

236 (schematic in Figure 3A) and observed only the larger species in WT LCAT $\mathrm{ARL}-\mathrm{HA}$. Together,

237 this strongly suggests that LCAT is processed at the TEXEL motif identified by TAILS (Table

238 1).

240 It is important to note that by immunofluorescence assays (IFA), we could only detect LCAT

241 within punctate structures within parasites, possibly the dense granules (Fig 3C), but not at the

242 PVM as has previously been reported (40). The absence of signal at the PVM suggests that the

243 introduction of the 3xHA tags or replacement of the endogenous 3' UTR with the DHFR 3' UTR

244 interfered with trafficking of this enzyme (Figure 3C). To overcome this, we attempted to

245 introduce a single HA tag into the endogenous locus as this has been shown not to affect

246 trafficking (40). However, despite several attempts we were unable to introduce this single HA-

247 tag into the endogenous LCAT locus without positive selection, and therefore we were unable to

248 assess any differences in localisation in LCAT between WT and $\triangle a s p 5$ parasites (data not

249 shown).

$251 \quad$ N-terminal peptide enrichment identifies novel dense granule proteins as ASP5 substrates. 
After validating the dense granule protein LCAT as an ASP5 substrate, we sought to investigate

253 novel and hypothetical candidates. One peptide arising after an RRL only in WT parasites was

254 Ac-SSSAILTGQQIGTYR (Table 1), mapping to a hypothetical protein (TGME49_208370),

255 which we have named GRA43. This protein was chosen for further investigation as the RRL

256 motif maps near the C-terminus of the protein prior to a predicted transmembrane domain,

257 similar to MYR1 (Figure 4A). GRA43 is annotated on ToxoDB as 'myosin heavy chain-like',

258 but further investigation has revealed limited homology to myosin, rendering it unlikely that this

259 protein is a true myosin (data not shown). To assess GRA43 as a potential ASP5 substrate, we

260 inserted a HA tag at the C-terminus in WT parasites and observed two species, one at

261 approximately $22 \mathrm{kDa}$ and another at $\sim 30 \mathrm{kDa}$, both well below the predicted size of $\sim 125 \mathrm{kDa}$

262 (Figure 4A and B). We then repeated this process in $\triangle a s p 5$ parasites, revealing the lowermost

263 band and a second at $\sim 140 \mathrm{kDa}$, indicating the loss of a processing event, dependent on this

264 aspartyl protease. To validate the RRL found by TAILS within this vicinity, we mutated the

$265 \mathrm{RRL} \rightarrow \mathrm{ARL}$ (Figure S1A) and again observed the same processing pattern as seen in $\triangle$ asp5

266 parasites, strongly suggesting that GRA43 is cleaved by ASP5 in a TEXEL-dependent manner.

267 The presence of the lowest molecular weight species in WT, ARL and $\Delta a s p 5$ parasites

268 potentially results from processing at or near the predicted transmembrane (TM) domain near the

269 C-terminus of this protein by a protease other than ASP5 (Figure 4A and B).

271 As both MYR1 and LCAT are cleaved by ASP5 near the C-terminus, and then the N- and C-

272 termini re-associate $(37,40)$, we sought to determine whether the same was true for GRA43. To

273 address this, we tagged GRA43 at the C-terminus with a TY tag, followed by a HA tag shortly

274 after the predicted signal peptidase cleavage site (Figure 4A). To determine the sub-cellular 
275 localisation of the two ASP5-processed sequences of GRA43, we probed extracellular parasites

276 with $\alpha$ Ty antibodies using super-resolution microscopy and observe a spherical donut-shaped

277 localisation that encloses GRA1 staining in dense granules, suggesting this protein resides at the

278 periphery of the dense granules (Figure 4C). We observe very low levels of co-localisation of the

279 N-terminal $(\alpha \mathrm{HA})$ and C-terminal ( $\alpha \mathrm{Ty})$ fragments of GRA43 in extracellular parasites (Figure

280 4C, bottom panel).

282 Immunoblot analysis of WT parasites expressing HA-GRA43-TY using $\alpha$ HA antibodies

283 revealed two bands at approximately 130 and $100 \mathrm{kDa}$, while only the higher molecular weight

284 species was present in $\Delta a s p 5$ parasites, suggesting a loss of processing (Fig 4Di). Using $\alpha$ Ty

285 antibodies the majority of this protein was detected at $\sim 40 \mathrm{kDa}$, while in $\triangle a s p 5$ parasites this

286 species was lost and the protein remained at a higher molecular weight, consistent with the full-

287 length protein (Figure 4Dii). As in Figure 4B, in both WT and $\Delta a s p 5$ parasites we observed a

288 consistent $\sim 30 \mathrm{kDa}$ band for GRA43 that is consistent with processing around the TM domain of

289 this protein by a protease other than ASP5 (Figure 4Dii).

291 We then proceeded with further assessment of the localisation of GRA43. To determine the

292 location of this protein during early infection, parasites were fixed at 3 hours post invasion,

293 which revealed the secretion of GRA1 into the PV, but GRA43 appeared to remain associated

294 with the dense granules (Figure 4E). At 24 hours post invasion, the N-terminal processed species

295 of GRA43 in WT and $\triangle a s p 5$ parasites localised to discrete puncta within the parasites, notably at

296 the anterior and posterior ends of the tachyzoites (Figure 4Fi). At this time point, the C-terminal

297 fragment also localised to similar spherical structures within the parasites, potentially dense 
granules (Figure 4Fii). We could detect no difference in localisation of the C-terminal fragment

299 between WT and $\Delta a s p 5$ parasites.

300 Together, these data reveal that GRA43 is processed by ASP5 near the C-terminus, and that it is

301 a dense granule protein based on the localisation of both cleaved fragments. The TEXEL of

302 GRA43 maps to the C-terminal end of this protein; however, unlike MYR1 and LCAT that are

303 cleaved by ASP5 within a similar region, the N- and C-terminal fragments of GRA43 do not

304 appear to re-associate. Similar to MYR1 and LCAT, we were unable to detect GRA43 within the

305 host cell, suggesting that it is not exported and raising the possibility that processing near the C-

306 terminal region could be a marker of non-exported ASP5 substrates.

308 Two WNG kinases are substrates of ASP5

309 Further investigation of our proteomic dataset revealed two proteins that were previously

310 annotated as rhoptry kinases through their similarity to ROP16, ROP18 and several other

311 predicted kinases (Table S1) (41). Here we present ROP35 (TGME49_304740) and ROP34

312 (TGME49_240090), herein named WNG1 and WNG2 respectively for reasons outlined below,

313 as novel ASP5 substrates. WNG1 was identified in the TAILS screen due to increased levels of

314 acetylated SP-cleaved peptide within $\Delta a s p 5$ parasites (Table 1), that mapped upstream of a

315 TEXEL motif, suggesting that the SP-cleavage site is the N-terminus in $\triangle$ asp5 parasites.

317 To determine the fate of WNG1, we epitope-tagged this protein at the C-terminus and monitored

318 its maturation by western blot (Figure 5A and B). We observed that WNG1 expressed by WT

319 parasites was present at $\sim 42 \mathrm{kDa}$, which is a smaller size than predicted by the full amino acid

320 sequence (Figure 5A). In contrast, epitope tagging in $\triangle a s p 5$ parasites revealed that WNG1 was 
321 present at a higher molecular weight, suggesting it is indeed processed by ASP5 (Figure 5B). To

322 assess whether WNG1 is processed within the predicted TEXEL motif, we mutated the

323 endogenous RRL $\rightarrow$ ARL (Figure S1B), and indeed, observed an accumulation of the higher

324 molecular weight species in these $\mathrm{WNG} 1_{\mathrm{ARL}}-\mathrm{HA}$ parasites (Figure $5 \mathrm{~B}$ ).

326 We then investigated the localisation of WNG1 by IFA and found no co-localisation with the

$327 \alpha \mathrm{ROP} 2 / 3 / 4$ marker in intracellular parasites, suggesting this predicted kinase is not a true rhoptry

328 protein (Figure 5Ci). The low level of HA signal observed using rabbit $\alpha \mathrm{HA}$ antibodies in WT

329 WNG1-HA expressing parasites (Figure 5Ci, upper panel) was more pronounced in $\triangle a s p 5$

330 parasites (lower panel), suggesting that loss of ASP5 leads to the accumulation of WNG1 within

331 localised areas in the PV, a phenomenon observed for several dense granule proteins following

332 deletion of ASP5 $(20,22)$ (Figure 5Ci). WT:WNG1-HA was primarily found within the vacuole

333 and exhibited partial co-localisation with the PV/PVM marker MAF1 (Figure 5Cii), as did

$334 \Delta a s p 5:$ WNG1-HA, suggesting WNG1 is a dense granule protein.

336 We then investigated WNG2 and its dependence on ASP5 for proteolytic maturation. Our N-

337 terminome data identified a peptide that mapped to WNG2 resulting from cleavage after an RRL

338 (dimethyl-DSLIPGFLKR) was observed in WT but not in $\triangle a s p 5$ parasites (Table 1). To confirm

339 if WNG2 is a true ASP5 substrate, we inserted a HA tag into the endogenous locus just before

340 the stop codon and observed the dominant species at $~ 55 \mathrm{kDa}$, despite the predicted molecular

341 weight of $\sim 62 \mathrm{kDa}$. In contrast, in parasites lacking ASP5, and those expressing the mutated

$342 \mathrm{RRL} \rightarrow \mathrm{ARL}\left(\mathrm{WNG} 2_{\mathrm{ARL}}-\mathrm{HA}\right.$, Figure S1D), this protein migrated at approximately $60 \mathrm{kDa}$,

343 strongly suggesting ASP5-dependent maturation (Figure 5E). 
345 We then investigated the localisation of WNG2 by IFA. As with WNG1, WNG2 did not co-

346 localise with the rhoptry marker $\alpha \mathrm{ROP} 2 / 3 / 4$ (Figure 5Fi). When probing with antibodies against

347 the PV/PVM protein MAF1 (Figure 5Fii), a small proportion of WNG2-HA expressed by WT

348 parasites co-localised at the PVM, however most was present within the parasites within the

349 donut-shaped spheres, similar to that described for GRA43, suggestive of dense granules (Figure

350 4C). In $\triangle a s p 5$ parasites, MAF1 loses a significant proportion of its PVM localisation, as has been

351 previously reported (20), and the WNG2-HA signal in $\triangle a s p 5$ parasites overlaps with the MAF1

352 signal detected in the PV space. Our data therefore strongly suggests that these kinases are

353 unlikely to represent bona fide rhoptry proteins and we have therefore renamed these proteins as

354 WNG kinases, short for 'With No Gly-loop' as they do not contain the characteristic glycine-rich

355 loop of other kinases. As ROP35 is the most conserved across Coccidia, we named this WNG1,

356 with ROP34 renamed as WNG2.

358 ASP5 matures the dense granule phosphatase GRA44 and a novel dense granule protein

360 Our N-terminome analyses discovered a peptide resulting from cleavage after an RRL within the

361 protein annotated as inner membrane complex protein 2A (IMC2A, TGME49_228170). For

362 reasons outlined below, we rename IMC2A to GRA44.

364 To investigate the maturation of GRA44 by ASP5 we introduced a HA tag shortly before the 365 endogenous stop codon in WT parasites (Figure 6A). We observed a species of $\sim 37 \mathrm{kDa}$, shorter 366 than the predicted $\sim 185 \mathrm{kDa}$ size of the full-length protein (Figure 6A and B). In contrast, this 
367 protein migrated close to $200 \mathrm{kDa}$ in $\triangle a s p 5$ parasites, suggesting the loss of one or more

368 processing events within these parasites. The RRL-cleaved peptide of GRA44, found in both the

369 dimethyl and HYTANE experiments, was observed only in WT parasites and maps near the

370 predicted SP-cleavage site. However, we were unable to mutate this endogenous RRL $\rightarrow$ ARL

371 despite several attempts, suggesting a fitness cost to the parasites (data not shown). Processing at

372 this N-terminal RRL could not account for the $\sim 37 \mathrm{kDa}$ species observed in WT parasites,

373 suggesting GRA44 is processed at least twice. Indeed, GRA44 contains a second RRL

374 approximately $32 \mathrm{kDa}$ from the C-terminus (Figure 6A) which may be processed by ASP5.

375

376 To investigate the importance of GRA44 on parasite growth we generated a knockout line by

377 integration of CAT selectable marker (Figure S1D), which led to the ablation of HA signal by

378 western blot (Figure 6B, longer exposure in Figure S3). Parasites lacking GRA44 ( $\operatorname{cra} r 4$ )

379 formed smaller plaques than WT parasites, yet the defect was not as severe as that observed for

$380 \triangle a s p 5$ parasites, despite having a lower CRISPR fitness score (42) (Figure 6C). In extracellular

381 parasites, GRA44 -HA signal enclosed a subset of GRA1-containing dense granules, similar to

382 GRA43 (Figure 6D, 4C). Immunofluorescence assays demonstrate a lack of co-localisation with

383 IMC1 in intracellular parasites, suggesting this protein is not part of the IMC, as its previous

384 annotation of IMC2A suggests, and instead localises within the PV and PVM in WT parasites

385 (Figure 6Ei, ii). In $\triangle a s p 5$ parasites this protein is observed primarily between parasites in the PV

386 instead of the PVM, similar to MAF1 (Figure 6E), as is common for dense granule proteins after

387 deletion of ASP5 (20-22). 
To further elucidate the mechanisms by which the novel ASP5 substrates operate, we performed

390 immunoprecipitations to assess whether any act within larger complexes. To address this, we

391 infected HFFs at a MOI of 5 with GRA43-HA, GRA44-HA and WNG2-HA parasites, then

392 harvested from large vacuoles at 36 hours post infection, lysed and then pulled down these

393 proteins using $\alpha \mathrm{HA}$ antibodies. IPs were performed in triplicate and protein eluates were

394 subjected to mass spectrometry analysis where protein expression changes were quantified using

395 a custom label-free pipeline. Each of the pulldowns enriched the bait (Figure S2), while also

396 enriching for several other dense granule proteins. TGME49_316250 (GRA45) was highly

397 enriched in GRA44-HA and WNG2-HA pulldowns compared to GRA43-HA (Supp. Fig 2) and

398 was chosen for further validation as it contains a signal peptide and a putative TEXEL motif.

400 To investigate TGME49_316250, which we herein rename GRA45, we epitope tagged this

401 protein just before the predicted stop codon. The dominant molecular weight species observed in

402 WT parasites was approximately $42 \mathrm{kDa}$, with a fainter band at $\sim 47 \mathrm{kDa}$ (Figure 6F). Deletion of

403 ASP5, or mutation of the RRL $\rightarrow$ ARL resulted in the loss of the lower migrating band,

404 suggesting this protein is indeed processed by ASP5 (Figure 6F). GRA45-HA was observed in

405 punctate structures within parasites and the PV space, primarily at the posterior of parasites (Fig

406 6G), somewhat overlapping with the dense granule protein MAF1. Similar localisation was

407 observed in $\triangle a s p 5$ parasites (not shown), suggesting this novel ASP5 substrate is a dense granule

408 protein.

409

410 WNG2 and GRA43 are important for virulence 
412 ROP kinases are important virulence factors (3-11), therefore we wanted to determine if the

413 WNG kinases also played important roles in vivo. We generated knockouts of WNG1, WNG2

414 and GRA43 (Figure S1 A, B and C) and confirmed loss of expression using western blot (Figure

415 7A, B and C). Furthermore, we generated knockout of ASP5 in a type II Pru background for

416 purposes of comparison (Figure S1E). As has been previously reported, murine infection with

417 less than $100 \mathrm{RH} \Delta$ asp5 parasites leads to attenuation in virulence (20, 22), however higher doses

418 render mice susceptible in a similar manner to infection with WT parasites. To confirm if this

419 was true for Pru $\Delta k u 80$ parasites, we injected six C57/BL6 mice with 2000 Pru $\Delta k u 80$ (WT) or

420 Pru $\Delta k u 80 \Delta a s p 5$ ( $\triangle a s p 5)$ parasites and observed complete attenuation in mice infected with

$421 \Delta a s p 5$, while all mice infected with WT parasites succumbed by day 8 (Figure 7D). The same

422 was true when infection was increased to 5,000 or 50,000 parasites (Fig 7E), with mice infected

423 with $\triangle$ asp5 parasites retaining their initial bodyweight (lower panel), despite exhibiting bloating

424 of the abdomen, a common response to infection.

426 We then sought to determine whether GRA43 and WNG2 are important for parasite virulence

427 during acute infection. To address this, we injected six C57/BL6 mice with $10^{3}$ Pru $\Delta k u 80 \mathrm{WT}$,

428 Pru $\Delta k u 80 \Delta g r a 43(\Delta g r a 43)$ and Pru $4 k u 80 \Delta w n g 2(\Delta w n g 2)$ tachyzoites then monitored infection

429 (Figure 7F). All mice infected with WT parasites gradually lost bodyweight throughout infection

430 and were culled between days 8-17. Mice infected with $\Delta g r a 43$ and $\Delta w n g 2$ parasites lost

431 bodyweight, however by day 17 the remaining mice began to recover. All mice infected with

$432 \Delta w n g 2$ parasites survived the infection, while 3/6 infected with $\Delta g r a 43$ were culled. All

433 surviving mice were seropositive for exposure to Toxoplasma (data not shown). Despite these 
434 defects we could not observe any growth defects in vitro, as monitored by plaque assay (Figure 435 S4).

437 After establishing that $\Delta g r a 43$ and $\Delta w n g 2$ tachyzoites have a mild virulence defect in vivo, we 438 sought to interrogate whether ASP5 cleavage is required for this virulence shift. To do this we 439 used tachyzoite lines harbouring RRL $\rightarrow$ ARL mutations (Figure S1) that are not proteolytically

440 processed (Figure 4B, 5B and 5E). We then infected C57/BL6 mice at a slightly higher inoculum

441 to further dissect out virulence defects (Figure 7G-I), and simultaneously performed plaque

442 assays, revealing all mice received the same infectious dose and there were no observable growth

443 defects in vitro for these strains (Figure S4). All mice infected with the parental WNG1-HA

444 strain were culled by day 11 post infection, while those infected with WNG1 $1_{\mathrm{ARL}}-\mathrm{HA}$ succumbed

445 between days 10-26 (Figure 7G). Three mice infected with $\Delta w n g 1$ parasites were culled

446 throughout the experiment, while a further three began to recover their initial bodyweight loss

447 (Figure 7G, lower panel) and survived until day 30 post-infection, when the experiment was

448 concluded. Differences in survival were assessed using the Log-rank (Mantel Cox) test, adjusted 449 according to the Bonferroni correction and were not statistically significant between any of the 450 strains.

452 Mice infected with the parental WNG2-HA parasite line were culled by day 10 post infection, 453 while all mice infected with $\mathrm{WNG} 2_{\mathrm{ARL}}-\mathrm{HA}$ parasites were moribund by day 15 (Fig $7 \mathrm{H}$ ). In 454 contrast, $3 / 6$ mice infected with $\Delta w n g 2$ parasites survived the experiment, despite stagnating at $455 \sim 90 \%$ of initial bodyweight between days 15-30 post infection. 
457 While infection with $1000 \Delta$ gra43 parasites led to an attenuation of virulence, this was not

458 replicated after the dose was doubled to 2000 parasites, suggesting this protein has a very modest

459 effect during acute infection (Figure 7F, I). In contrast, $\Delta w n g 2$ parasites were significantly less

460 virulent than WT parasites at both doses, indicating an important function during acute infection.

461 Furthermore, for all TEXEL proteins assessed in this experiment, there was no statistical

462 difference between WT and RRL $\rightarrow$ ARL mutants, suggesting that for these non-exported ASP5

463 substrates, efficient processing by ASP5 is not essential for their function during murine

464 infection.

465 


\section{$\underline{\text { Discussion }}$}

467 Toxoplasma uses a repertoire of secreted and exported proteins to exquisitely modulate the host 468 response to infection. Initial host cell subversion is achieved through the secretion of the rhoptry 469 proteins, notably ROP16 and ROP5/18 (3-5). Following establishment of the PV, Toxoplasma 470 translocates a second wave of proteins across the PVM. These include two ASP5-cleaved

471 exported proteins, GRA16 and IST, that Toxoplasma employs to regulate the cell cycle and avoid

472 clearance from cells following IFN $\gamma$ signalling, respectively. Furthermore, GRA24 does not

473 appear to be processed by ASP5, yet its translocation across the PVM is still dependent on this

474 protease $(16,20-22)$. Interestingly, the translocation of these proteins into the host cell requires

475 the PVM protein MYR1, another ASP5 substrate. Despite the importance of this protease, only a

476 handful of ASP5 substrates have been described to date. To address this shortcoming and

477 identify new Toxoplasma effectors and virulence factors, we have exploited the differences in N-

478 termini between WT and $\triangle a s p 5$ parasites using a quantitative proteomics approach in

479 combination with N-terminal enrichment methods. In doing so, we have discovered several new

480 effectors. We have validated several of these substrates, including confirmation of their

481 processing by ASP5.

483 Here we have presented that WNG1, WNG2, GRA44, GRA43 and GRA45 are processed by

484 ASP5. Notably, immunofluorescence of each of these proteins has revealed they are at least

485 transient components of the dense granules. It is currently unclear whether ASP5 processes

486 substrates from other organelles, including the micronemes and the rhoptries, however, proteins

487 from these organelles have recently been demonstrated to be processed by aspartyl protease 3

488 (ASP3) (43), suggesting different proteases may function in maturation of proteins destined for 
490 validated substrates into the PV/PVM, with no signal detected within the host cell. However, we

491 cannot preclude that some of these proteins are indeed translocated across the PVM but

492 subsequently are highly diluted and unable to be detected through normal immunofluorescence

493 imaging. Indeed, the four characterised exported proteins GRA16, GRA24, GRA28 and IST all

494 traffic to the host nucleus $(14,16-19)$, potentially concentrating their signal above levels that

495 could be detected if they were throughout the cytosol.

497 Unlike in Plasmodium, the TEXEL sequence in Toxoplasma appears not to be spatially

498 restricted. The identification of new ASP5 substrates within this manuscript confirms that the

499 TEXEL can be found anywhere throughout the protein. However, this motif in the two exported

500 substrates, GRA16 and IST, is located approximately 40 and 70 amino acids from the predicted

501 SP cleavage site, or at 13 and $16 \%$ of the protein length respectively. As GRA44 is also

502 processed within this approximate region, cleavage by ASP5 alone cannot dictate translocation

503 across the PVM. It is possible ASP5 processing potentially liberates an export signal, such as the

504 linear or structural sequence of amino acids revealed following cleavage, a suggestion that has

505 also been raised for export of PEXEL proteins (28). To address this, both a non-exported and an

506 exported protein should be monitored for their ability to translocate the PVM following targeted

507 mutagenesis of the TEXEL and surrounding residues. This could reveal whether residues either

508 upstream or downstream of cleavage are important for subsequent trafficking and ultimately

509 export into the host cell. 
511 We have demonstrated that two proteins previously predicted to be rhoptry kinases instead

512 appear to be dense granule proteins. Importantly, both WNG1 and WNG2 contain the key kinase

513 sequence motifs, suggesting they should be active within the dense granules and/or PV space.

514 WNG1 (ROP35) was recently knocked out in Pru $\Delta k u 80$ parasites, as part of a wider screen to

515 identify the role of the predicted rhoptry kinases during chronic infection (44). Interestingly,

516 although $\Delta w n g 1$ parasites retained the ability to differentiate into bradyzoites in vitro, parasites

517 lacking this kinase formed approximately $75 \%$ fewer tissue cysts within the brains of infected

518 mice, suggesting WNG1 plays a role in the development or persistence of bradyzoites (44).

519 Kinases have already been extensively explored as effector proteins in Toxoplasma, ranging

520 from the secreted ROP16 and ROP18, to the recently described (dense granule protein kinases)

521 annotated as ROP21 and ROP27 (45). While these kinases have been characterised at the host-

522 parasite interface, no phosphatases had been reported at this location. In light of this, a novel

523 finding in this study was the localisation of GRA44 at the PVM. This is the first example of a

524 phosphatase that lies at the interface of this important boundary. Interestingly, GRA44 has a

525 CRISPR score of -3.28 (42), lower than ASP5's score of -1.45 , which suggested that this protein

526 is important for in vitro growth. This CRISPR score was validated as $\Delta$ gra44 parasites exhibited

527 a growth defect in vitro, a phenotype that has not previously been observed for ASP5-cleaved

528 dense granule proteins, including GRA16 and MYR1, despite parasites lacking both of these

529 proteins displaying a substantial virulence defect in vivo $(14,37)$. Finally, GRA44 was originally

530 predicted to localise to the IMC based on an antibody that recognised the cytoplasmic face of the

531 IMC, whose target was named IMC2 (46). The current version (v34) of ToxoDB does not

532 recognise a protein termed $\mathrm{IMC} 2$, and the sequence used to immunise mice to generate the

533 original IMC2 antibody is no longer annotated as part of IMC2A. 
535 To assess the role of these newly described ASP5 substrates in vivo, we employed a mouse

536 model to assess Toxoplasma infection in C57BL/6 mice. As a control, we inoculated mice with

537 up to 50,000 Pru $\triangle k u 80 \Delta a s p 5$ ( $\triangle a s p 5)$ tachyzoites and observed complete attenuation in

538 virulence, while mice infected with proportional numbers of WT parasites succumbed during this

539 time period. To validate the role of ASP5 cleavage in virulence for WNG1, WNG2 and GRA43,

540 we infected mice with an RRL $\rightarrow$ ARL mutations, or knockouts. Surprisingly for each substrate

541 we observed no significant difference in virulence for mice infected with WT parasites compared

542 to RRL $\rightarrow$ ARL parasites. These data suggest that at least for these non-exported proteins,

543 efficient ASP5 processing is not required for their trafficking to the dense granules, PV and/or

544 PVM. This however, does not discount that a small amount of protein may still be cleaved and

545 this is enough to fulfil its function.

547 It is clear that there are more ASP5 substrates than we have identified. Not all ASP5 substrates

548 were detected in our analyses, including GRA16 and MYR1. There are a several potential

549 reasons for this, with two of the most likely being: 1. The ASP5-cleaved protein may be of low

550 abundance in sampled parasites, and 2. The subsequent peptide difficult to enrich or not suitable

551 for detection by mass spectrometry. The former point is supported by a recent study utilising

552 TAILS to identify substrates of ASP3 in Toxoplasma (43). ASP3 processes microneme and

553 rhoptry proteins that are generally more abundant than the dense granule proteins, potentially

554 enabling greater substrate identification. Furthermore, it is likely that ASP3 substrates greatly

555 outnumber ASP5 substrates. Overall, whilst it is clear that using two different methodologies (ie 
556 TAILS and HYTANE) to enrich for N-terminal peptides was beneficial $(38,39)$ it is clear that

557 other methodologies will need to be adopted to identify a more ASP5 substrates.

558

559 In conclusion, we have used N-terminomics to identify novel substrates of the important protease

560 ASP5, and validated a subset of these through tagging and mutagenesis of the endogenous locus

561 within parasites. Deletion of several of these corresponded to a reduction in virulence during

562 murine infection, but not to the same extent as infection with $\triangle a s p 5$ parasites, suggesting the

563 dramatic reduction in virulence during $\triangle a s p 5$ infection results from many effectors that are not

564 trafficked correctly. Overall, our data validate the essential role of ASP5 during infection and

565 that the conserved RRL motif is critical for cleavage by this protease. 


\section{Materials and Methods}

568 Toxoplasma transfection and growth.

569 Candidate genes were tagged endogenously within parasites using the CRISPR/Cas9 system

570 which has been adapted for use in Toxoplasma $(47,48)$. Briefly, genes were tagged just prior to

571 the endogenous stop codon following guide selection from EuPaGDT

572 (http://grna.ctegd.uga.edu/batch_tagging.html). The CRISPR target plasmid (made by Q5

573 mutagenesis, NEB) was co-transfected with homologous repair constructs containing, Ty- or

574 HA-epitope tag as previously described (20). Two oligos with at least $30 \mathrm{bp}$ of complementarity

575 at their 3' end, usually over the HA- or TY-epitope, were annealed together in IDT-duplex buffer

576 by heating to $98^{\circ} \mathrm{C}$ for two minutes then gradually allowed to cool (47). $10 \mathrm{ug}$ of Cas9 plasmid

577 was combined with the total $80 \mathrm{ug}$ of annealed oligos, amd resuspended in $20 \mathrm{uL} \mathrm{P3}$ solution

578 (Lonza), in an Amaxa 4D Nucleofector (Lonza) using the code FI-115 (Human Unstimulated T-

579 cells). Human foreskin fibroblasts were grown to confluency in Dulbecco's Modified Eagle

580 Medium (DMEM), supplemented with 10\% Cosmic Calf serum (Hyclone) and refreshed with

581 DMEM with $1 \%$ fetal calf serum when inoculated with parasites.

\section{$583 \quad$ PCR and plasmid construction}

584 Please consult supplementary text for details.

586 Immunofluorescence Assays (IFAs) and microscopy

587 Fixation, preparation of reagents and mounting for IFAs were performed as previously described 588 (20). All images were captured on the Zeiss LSM 880 with Airyscan Detector. Before each 
589 session, channel alignment was performed using a FocalCheck fluorescence microscope test

590 slide \#1 (ThermoFisher) and subsequent images were automatically aligned in FIJI using the

591 plugin TransformJ Translate.

592

593 Western Blots

594 Immunoblot samples were pelleted then lysed for $30 \mathrm{mins}$ at $4{ }^{\circ} \mathrm{C}$ in $1 \% \mathrm{v} / \mathrm{v}$ Triton-X 100

595 (brand), $1 \mathrm{mM} \mathrm{MgCl}$ in PBS (Gibco) supplemented with final 1 x cOmplete protease inhibitors

596 (Sigma) and $0.2 \%$ v/v Benzonase (Merck). Samples were then combined with an equal volume

597 of $2 x$ Sample buffer and $20 \mu$ loaded onto a gel. Proteins were transferred onto nitrocellulose

598 (brand) then blocked in $5 \%$ w/v milk in $0.05 \%$ Tween 20-supplemented PBS. Primary and

599 secondary antibodies were diluted in milk/PBS. For LI-COR Western blots, the membranes were

600 imaged on an Odyssey Fc imager (LI-COR Biosciences) using IRDye 800CW goat $\alpha$-rat, IRDye

601 800CW goat $\alpha$-mouse and IRDye 680RD goat $\alpha$-rabbit antibodies. Antibodies used in this study

602 were: $\alpha \mathrm{HA} 3 \mathrm{~F} 10$ (Roche), $\alpha \mathrm{HA}$ (Rabbit, in house), $\alpha$ TY1 BB2 (ThermoFisher), $\alpha \mathrm{GAP} 45$ (49),

$603 \alpha$ GRA1 (50), $\alpha$ MAF1 (13), $\alpha \mathrm{IMC1}$ (G. Ward, University of Vermont) and $\alpha \mathrm{ROP} 2 / 3 / 4$ (51).

604

605 Quantitative Proteomics

606 Please consult supplementary text for details on SILAC labelling, protein extraction, TAILS and

607 HYTANE purification, $\mathrm{pH}$ fractionation, LC MS/MS and data analysis

608

609 Virulence Experiments

610 All mouse experiments were conducted within the regulations of the Walter and Eliza Hall's

611 Animal Ethics Committee (AEC). Pru $\Delta k u 80 \Delta \mathrm{hx}$ (WT), Pru $\Delta k u 80 \Delta h x \Delta a s p 5$ (4asp5), 


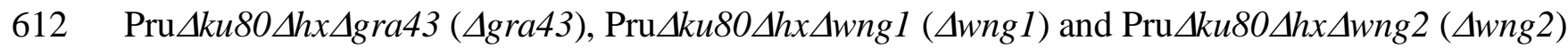

613 parasites were grown in HFFs until $~ 10 \%$ lysed, then scraped and released from host cells by

614 passage through a $27 \mathrm{~g}$ needle. Parasites were then counted and resuspended at the indicated dose

615 in $200 \mu \mathrm{l}$ PBS then injected intraperitoneally into 6 x 6-8-week-old C57BL/6 mice. Mice were

616 weighed daily and culled after exhibiting bodyweight loss of greater than $15 \%$ for three

617 consecutive days if they were not going to recover (as per the WEHI AEC) or when moribund.

618 All surviving mice were sacrificed 30 days after infection and the resulting cardiac bleed serum

619 was used as a 1/50 dilution primary antibody to check for seroconversion against tachyzoite

620 lysate.

621

$622 \underline{\text { Datasets }}$

623 The mass spectrometry proteomics data have been deposited to the ProteomeXchange (52)

624 Consortium via the PRIDE (53) partner repository with the dataset identifier PXD008574.

625 Reviewer account details:

626 Username: reviewer59728@ebi.ac.uk

627 Password: $\mathrm{nHec} 97 \mathrm{Mb}$

629 Funding information

630 This work was supported by an Australian Research Council (ARC) Future Fellowship (CJT)

631 and the David Winston Turner Trust (CJT). We are also grateful for institutional support from

632 the Victorian State Government Operational Infrastructure Support and the Australian

633 Government NHMRC IRIISS.The funding agencies had no role in the study design, data

634 collection and interpretation, or the decision to submit the work for publication. 


\section{Acknowledgements}

637 We would like to thank Carolina Alvarado from WEHI Bioservices for her handling and

638 maintenance of the infected mice. Ellen Yeh from Stanford for data and protocol sharing and for

639 graciously accepting Michael Coffey into her laboratory where learnt the TAILS methodology

640 with Katrina Hong. John Boothroyd, Mike Panas and Nicole Marino from Stanford for continual

641 sharing of unpublished data, and the suggested nomenclature on the WNG kinases from Michael

642 Reese at UT Southwestern. 


\section{References:}

1. Glasner PD, Silveira C, Kruszon-Moran D, Martins MC, Burnier Junior M, Silveira S, Camargo ME, Nussenblatt RB, Kaslow RA, Belfort Junior R. 1992. An unusually high prevalence of ocular toxoplasmosis in southern Brazil. Am J Ophthalmol 114:136-44.

5. Taylor S, Barragan A, Su C, Fux B, Fentress SJ, Tang K, Beatty WL, Hajj HE, Jerome M,

7. Rosowski EE, Saeij JP. 2012. Toxoplasma gondii clonal strains all inhibit STAT1

3. Saeij JP, Boyle JP, Coller S, Taylor S, Sibley LD, Brooke-Powell ET, Ajioka JW, Boothroyd Mourvillier B, Wolff M. 2011. Neurological complications of HIV infection in critically ill

2. Sonneville R, Ferrand H, Tubach F, Roy C, Bouadma L, Klein IF, Foucrier A, Regnier B,

JC. 2006. Polymorphic secreted kinases are key virulence factors in toxoplasmosis.

4. Saeij JP, Coller S, Boyle JP, Jerome ME, White MW, Boothroyd JC. 2007. Toxoplasma coopts host gene expression by injection of a polymorphic kinase homologue. Nature 445:324-7. Behnke MS, White M, Wootton JC, Sibley LD. 2006. A secreted serine-threonine kinase determines virulence in the eukaryotic pathogen Toxoplasma gondii. Science 314:177680.

6. Jensen KD, Hu K, Whitmarsh RJ, Hassan MA, Julien L, Lu D, Chen L, Hunter CA, Saeij JP. 2013. Toxoplasma gondii rhoptry 16 kinase promotes host resistance to oral infection and intestinal inflammation only in the context of the dense granule protein GRA15. Infect Immun 81:2156-67. transcriptional activity but polymorphic effectors differentially modulate IFNgamma induced gene expression and STAT1 phosphorylation. PLoS One 7:e51448.

8. Yamamoto $M$, Standley DM, Takashima S, Saiga H, Okuyama M, Kayama H, Kubo E, Ito H, Takaura M, Matsuda T, Soldati-Favre D, Takeda K. 2009. A single polymorphic amino acid on Toxoplasma gondii kinase ROP16 determines the direct and strain-specific activation of Stat3. J Exp Med 206:2747-60.

9. Ong YC, Reese ML, Boothroyd JC. 2010. Toxoplasma rhoptry protein 16 (ROP16) subverts host function by direct tyrosine phosphorylation of STAT6. J Biol Chem 285:28731-40.

10. Khaminets A, Hunn JP, Konen-Waisman S, Zhao YO, Preukschat D, Coers J, Boyle JP, Ong YC, Boothroyd JC, Reichmann G, Howard JC. 2010. Coordinated loading of IRG resistance GTPases on to the Toxoplasma gondii parasitophorous vacuole. Cell Microbiol 12:93961.

11. Niedelman W, Gold DA, Rosowski EE, Sprokholt JK, Lim D, Farid Arenas A, Melo MB, Spooner E, Yaffe MB, Saeij JP. 2012. The rhoptry proteins ROP18 and ROP5 mediate Toxoplasma gondii evasion of the murine, but not the human, interferon-gamma response. PLoS Pathog 8:e1002784. 
12. Rosowski EE, Lu D, Julien L, Rodda L, Gaiser RA, Jensen KD, Saeij JP. 2011. Strain-specific activation of the NF-kappaB pathway by GRA15, a novel Toxoplasma gondii dense granule protein. J Exp Med 208:195-212.

13. Pernas L, Adomako-Ankomah Y, Shastri AJ, Ewald SE, Treeck M, Boyle JP, Boothroyd JC. 2014. Toxoplasma effector MAF1 mediates recruitment of host mitochondria and impacts the host response. PLoS Biol 12:e1001845.

14. Bougdour A, Durandau E, Brenier-Pinchart MP, Ortet $P$, Barakat $M$, Kieffer S, CurtVaresano A, Curt-Bertini RL, Bastien O, Coute Y, Pelloux H, Hakimi MA. 2013. Host cell subversion by Toxoplasma GRA16, an exported dense granule protein that targets the host cell nucleus and alters gene expression. Cell Host Microbe 13:489-500.

15. Bougdour A, Tardieux I, Hakimi MA. 2014. Toxoplasma exports dense granule proteins beyond the vacuole to the host cell nucleus and rewires the host genome expression. Cell Microbiol 16:334-43.

16. Braun L, Brenier-Pinchart MP, Yogavel $M$, Curt-Varesano $A$, Curt-Bertini RL, Hussain $T$, Kieffer-Jaquinod S, Coute Y, Pelloux H, Tardieux I, Sharma A, Belrhali H, Bougdour A, Hakimi MA. 2013. A Toxoplasma dense granule protein, GRA24, modulates the early immune response to infection by promoting a direct and sustained host p38 MAPK activation. J Exp Med 210:2071-86.

17. Gay G, Braun L, Brenier-Pinchart MP, Vollaire J, Josserand V, Bertini RL, Varesano A, Touquet B, De Bock PJ, Coute Y, Tardieux I, Bougdour A, Hakimi MA. 2016. Toxoplasma gondii TgIST co-opts host chromatin repressors dampening STAT1-dependent gene regulation and IFN-gamma-mediated host defenses. J Exp Med 213:1779-98.

18. Olias P, Etheridge RD, Zhang Y, Holtzman MJ, Sibley LD. 2016. Toxoplasma Effector Recruits the Mi-2/NuRD Complex to Repress STAT1 Transcription and Block IFN-gammaDependent Gene Expression. Cell Host Microbe 20:72-82.

19. Nadipuram SM, Kim EW, Vashisht AA, Lin AH, Bell HN, Coppens I, Wohlschlegel JA, Bradley PJ. 2016. In Vivo Biotinylation of the Toxoplasma Parasitophorous Vacuole Reveals Novel Dense Granule Proteins Important for Parasite Growth and Pathogenesis. MBio 7.

20. Coffey MJ, Sleebs BE, Uboldi AD, Garnham A, Franco M, Marino ND, Panas MW, Ferguson DJ, Enciso M, O'Neill MT, Lopaticki S, Stewart RJ, Dewson G, Smyth GK, Smith BJ, Masters SL, Boothroyd JC, Boddey JA, Tonkin CJ. 2015. An aspartyl protease defines a novel pathway for export of Toxoplasma proteins into the host cell. Elife 4.

21. Curt-Varesano A, Braun L, Ranquet C, Hakimi MA, Bougdour A. 2016. The aspartyl protease TgASP5 mediates the export of the Toxoplasma GRA16 and GRA24 effectors into host cells. Cell Microbiol 18:151-67.

22. Hammoudi PM, Jacot D, Mueller C, Di Cristina M, Dogga SK, Marq JB, Romano J, Tosetti N, Dubrot J, Emre Y, Lunghi M, Coppens I, Yamamoto M, Sojka D, Pino P, Soldati-Favre D. 2015. Fundamental Roles of the Golgi-Associated Toxoplasma Aspartyl Protease, ASP5, at the Host-Parasite Interface. PLoS Pathog 11:e1005211.

23. Coffey MJ, Jennison C, Tonkin CJ, Boddey JA. 2016. Role of the ER and Golgi in protein export by Apicomplexa. Curr Opin Cell Biol 41:18-24. 
24. Boddey JA, Hodder AN, Gunther S, Gilson PR, Patsiouras H, Kapp EA, Pearce JA, de

25. Russo I, Babbitt S, Muralidharan V, Butler T, Oksman A, Goldberg DE. 2010. Plasmepsin V licenses Plasmodium proteins for export into the host erythrocyte. Nature 463:632-6.

26. Hiller NL, Bhattacharjee S, van Ooij C, Liolios K, Harrison T, Lopez-Estrano C, Haldar K. 2004. A host-targeting signal in virulence proteins reveals a secretome in malarial infection. Science 306:1934-7.

27. Marti M, Good RT, Rug M, Knuepfer E, Cowman AF. 2004. Targeting malaria virulence and remodeling proteins to the host erythrocyte. Science 306:1930-3.

28. Boddey JA, Moritz RL, Simpson RJ, Cowman AF. 2009. Role of the Plasmodium export element in trafficking parasite proteins to the infected erythrocyte. Traffic 10:285-99.

29. de Koning-Ward TF, Gilson PR, Boddey JA, Rug M, Smith BJ, Papenfuss AT, Sanders PR, Lundie RJ, Maier AG, Cowman AF, Crabb BS. 2009. A newly discovered protein export machine in malaria parasites. Nature 459:945-9.

30. Boddey JA, Carvalho TG, Hodder AN, Sargeant TJ, Sleebs BE, Marapana D, Lopaticki S, Nebl T, Cowman AF. 2013. Role of plasmepsin V in export of diverse protein families from the Plasmodium falciparum exportome. Traffic 14:532-50.

31. Boddey JA, Cowman AF. 2013. Plasmodium nesting: remaking the erythrocyte from the inside out. Annu Rev Microbiol 67:243-69.

32. Sleebs BE, Gazdik M, O'Neill MT, Rajasekaran P, Lopaticki S, Lackovic K, Lowes K, Smith BJ, Cowman AF, Boddey JA. 2014. Transition state mimetics of the Plasmodium export element are potent inhibitors of Plasmepsin V from P. falciparum and P. vivax. J Med Chem 57:7644-62.

33. Sleebs BE, Lopaticki S, Marapana DS, O'Neill MT, Rajasekaran P, Gazdik M, Gunther S, Whitehead LW, Lowes KN, Barfod L, Hviid L, Shaw PJ, Hodder AN, Smith BJ, Cowman AF, Boddey JA. 2014. Inhibition of Plasmepsin V activity demonstrates its essential role in protein export, PfEMP1 display, and survival of malaria parasites. PLoS Biol 12:e1001897.

34. Hodder AN, Sleebs BE, Czabotar PE, Gazdik M, Xu Y, O'Neill MT, Lopaticki S, Nebl T, Triglia T, Smith BJ, Lowes K, Boddey JA, Cowman AF. 2015. Structural basis for plasmepsin $\mathrm{V}$ inhibition that blocks export of malaria proteins to human erythrocytes. Nat Struct Mol Biol 22:590-6.

35. Beck JR, Muralidharan V, Oksman A, Goldberg DE. 2014. PTEX component HSP101 mediates export of diverse malaria effectors into host erythrocytes. Nature 511:592-5.

36. Elsworth B, Matthews K, Nie CQ, Kalanon M, Charnaud SC, Sanders PR, Chisholm SA, Counihan NA, Shaw PJ, Pino P, Chan JA, Azevedo MF, Rogerson SJ, Beeson JG, Crabb BS, Gilson PR, de Koning-Ward TF. 2014. PTEX is an essential nexus for protein export in malaria parasites. Nature 511:587-91.

37. Franco M, Panas MW, Marino ND, Lee MC, Buchholz KR, Kelly FD, Bednarski JJ, Sleckman BP, Pourmand N, Boothroyd JC. 2016. A Novel Secreted Protein, MYR1, Is Central to Toxoplasma's Manipulation of Host Cells. MBio 7:e02231-15.

38. Kleifeld O, Doucet A, auf dem Keller U, Prudova A, Schilling O, Kainthan RK, Starr AE, Foster L, Kizhakkedathu JN, Overall CM. 2010. Isotopic labeling of terminal amines in 
complex samples identifies protein $\mathrm{N}$-termini and protease cleavage products. Nat Biotechnol 28:281-8.

39. Chen L, Shan Y, Weng Y, Sui Z, Zhang X, Liang Z, Zhang L, Zhang Y. 2016. Hydrophobic Tagging-Assisted N-Termini Enrichment for In-Depth N-Terminome Analysis. Anal Chem 88:8390-5.

40. Pszenny V, Ehrenman K, Romano JD, Kennard A, Schultz A, Roos DS, Grigg ME, Carruthers VB, Coppens I. 2016. A Lipolytic Lecithin:Cholesterol Acyltransferase Secreted by Toxoplasma Facilitates Parasite Replication and Egress. J Biol Chem 291:3725-46.

41. Peixoto L, Chen F, Harb OS, Davis PH, Beiting DP, Brownback CS, Ouloguem D, Roos DS. 2010. Integrative genomic approaches highlight a family of parasite-specific kinases that regulate host responses. Cell Host Microbe 8:208-18.

42. Sidik SM, Huet D, Ganesan SM, Huynh MH, Wang T, Nasamu AS, Thiru P, Saeij JP, Carruthers VB, Niles JC, Lourido S. 2016. A Genome-wide CRISPR Screen in Toxoplasma Identifies Essential Apicomplexan Genes. Cell 166:1423-1435 e12.

43. Dogga SK, Mukherjee B, Jacot D, Kockmann T, Molino L, Hammoudi PM, Hartkoorn RC, Hehl AB, Soldati-Favre D. 2017. A druggable secretory protein maturase of Toxoplasma essential for invasion and egress. Elife 6.

44. Fox BA, Rommereim LM, Guevara RB, Falla A, Hortua Triana MA, Sun Y, Bzik DJ. 2016. The Toxoplasma gondii Rhoptry Kinome Is Essential for Chronic Infection. MBio 7.

45. Jones NG, Wang Q, Sibley LD. 2017. Secreted protein kinases regulate cyst burden during chronic toxoplasmosis. Cell Microbiol 19.

46. Mann T, Beckers C. 2001. Characterization of the subpellicular network, a filamentous membrane skeletal component in the parasite Toxoplasma gondii. Mol Biochem Parasitol 115:257-68.

47. Sidik SM, Hackett CG, Tran F, Westwood NJ, Lourido S. 2014. Efficient genome engineering of Toxoplasma gondii using CRISPR/Cas9. PLoS One 9:e100450.

48. Shen B, Brown KM, Lee TD, Sibley LD. 2014. Efficient gene disruption in diverse strains of Toxoplasma gondii using CRISPR/CAS9. MBio 5:e01114-14.

49. Gaskins E, Gilk S, DeVore N, Mann T, Ward G, Beckers C. 2004. Identification of the membrane receptor of a class XIV myosin in Toxoplasma gondii. J Cell Biol 165:383-93.

50. Cesbron-Delauw MF, Guy B, Torpier G, Pierce RJ, Lenzen G, Cesbron JY, Charif H, Lepage $P$, Darcy F, Lecocq JP, et al. 1989. Molecular characterization of a 23-kilodalton major antigen secreted by Toxoplasma gondii. Proc Natl Acad Sci U S A 86:7537-41.

51. Sadak A, Taghy Z, Fortier B, Dubremetz JF. 1988. Characterization of a family of rhoptry proteins of Toxoplasma gondii. Mol Biochem Parasitol 29:203-11.

52. Deutsch EW, Csordas A, Sun Z, Jarnuczak A, Perez-Riverol Y, Ternent T, Campbell DS, Bernal-Llinares M, Okuda S, Kawano S, Moritz RL, Carver JJ, Wang M, Ishihama $Y$, Bandeira N, Hermjakob H, Vizcaino JA. 2017. The ProteomeXchange consortium in 2017: supporting the cultural change in proteomics public data deposition. Nucleic Acids Res 45:D1100-D1106.

53. Vizcaino JA, Csordas A, del-Toro N, Dianes JA, Griss J, Lavidas I, Mayer G, Perez-Riverol Y, Reisinger F, Ternent T, Xu QW, Wang R, Hermjakob H. 2016. 2016 update of the PRIDE database and its related tools. Nucleic Acids Res 44:D447-56. 
bioRxiv preprint doi: https://doi.org/10.1101/271676; this version posted February 26, 2018. The copyright holder for this preprint (which was not certified by peer review) is the author/funder. All rights reserved. No reuse allowed without permission.

812 54. Petersen TN, Brunak S, von Heijne G, Nielsen H. 2011. SignalP 4.0: discriminating signal 813 peptides from transmembrane regions. Nat Methods 8:785-6.

814 
815 Table 1: - List of peptides found in the combined TAILS and HYTANE datasets and

816 subsequently validated as ASP5 substrates. Location of the peptide and three preceding amino

817 acids were obtained from Toxodb.org v34. (fi) = fixed dimethylation from SILAC experiments;

$818(\mathrm{n})=$ fixed dimethylation in HYTANE experiment; $(\mathrm{Ac})=$ acetylation occurring within parasites

819 and/or host cell. The HYTANE experiment did not use differential labelling so we could not

820 directly compare ratios between WT vs $\Delta a s p 5$; therefore, results are displayed as number of

821 samples the peptide was detected in per condition, $\mathrm{n}=9$ (3 independent biological samples,

822 performed in triplicate, with the HYTANE procedure performed once to reduce variation).

$823{ }^{a}$ We were unable to determine which samples (WT or $\triangle a s p 5$ ) the RRL-cleaved peptide

824 [(ac)AAEGGSESEDEQGVAR] originated from, as this was only found in the Dimethyl

825 experiment and contains no differential heavy/light dimethylation, as the N-terminus is blocked

826 and no there are no lysine residues. ${ }^{\mathrm{b}}$ Peptide for TGME49_286530 found in both WT and $\triangle$ asp5

827 parasites and maps within predicted SP, suggesting this processing is mediated by signal

828 peptidase. ${ }^{c}$ We have annotated the peptide mapping to WNG1 [(Ac)TVAAPQVETGPLLSVR]

829 as potentially SP cleaved, however SignalP 4.1 (54) does not recognise a signal peptide within

830 this protein. This annotation is based on the peptide being $\mathrm{N}$-acetylated, a modification observed

831 predominantly at the initiator methionine, SP cleavage site and the ASP5 cleavage site. Spectra

832 for HYTANE peptides can be found in Figure S5. 


\begin{tabular}{|c|c|c|c|c|c|c|}
\hline \multicolumn{7}{|c|}{ Found following RRL (validated) } \\
\hline Gene name & $\begin{array}{l}\text { Gene ID } \\
\text { (TGME49_) }\end{array}$ & $\begin{array}{l}\text { Sequence } \\
\text { Preceding } \\
\text { (and } \\
\text { location) }\end{array}$ & Peptide found & $\begin{array}{l}\text { Up in } \\
\text { WT or } \\
\text { Lasp5? }\end{array}$ & $\begin{array}{l}\text { Experiment } \\
\text { found }\end{array}$ & $\begin{array}{l}\text { Ratio of } \\
\text { WT/ } / \text { asp5 } 5 \\
\text { or if } \\
\text { HYTANE, } \\
\text { \# samples } \\
\text { detected in }\end{array}$ \\
\hline LCAT & 272420 & $\mathrm{RRL}^{476-478}$ & (fi)DAVLTDEVGGPESGAR & WT & $\begin{array}{l}\text { SILAC } \\
\text { (TAILS) }\end{array}$ & $5.61 / 0.14$ \\
\hline GRA43 & 208370 & $\mathrm{RRL}^{894-896}$ & (fi)LSSSAILTGQQIGTYR & WT & $\begin{array}{l}\text { SILAC } \\
\text { (TAILS) }\end{array}$ & $6.65 / 0.21$ \\
\hline GRA43 & 208370 & $\mathrm{RRL}^{894-896}$ & (n)LSSSAILTGQQIGTYR & WT & $\begin{array}{l}\text { LFQ } \\
\text { (HYTANE) }\end{array}$ & $\begin{array}{l}\text { 8/9 WT, } \\
0 / 9 \triangle a s p 5\end{array}$ \\
\hline $\begin{array}{l}\text { GRA44 } \\
\text { (IMC2A) }\end{array}$ & 228170 & $\mathrm{RRL}^{83-85}$ & (Ac)SGIIKTLVLWDPVQR & WT & $\begin{array}{l}\text { LFQ } \\
\text { (HYTANE) }\end{array}$ & $\begin{array}{l}\text { 4/9 WT, } \\
0 / 9 \triangle \operatorname{asp5}\end{array}$ \\
\hline $\begin{array}{l}\text { WNG2 } \\
\text { (ROP34) }\end{array}$ & 240090 & $\mathrm{RRL}^{109-111}$ & (n)DSLIPGFLKR & WT & $\begin{array}{l}\text { LFQ } \\
\text { (HYTANE) }\end{array}$ & $\begin{array}{l}\text { 6/9 WT, } \\
0 / 9 \triangle \operatorname{asp5}\end{array}$ \\
\hline IST & 240060 & $\mathrm{RRL}^{137-139}$ & _(ac)AAEGGSESEDEQGVAR & $\begin{array}{l}\text { No } \\
\text { ratio }^{a}\end{array}$ & $\begin{array}{l}\text { Dimethyl } \\
\text { (TAILS) }\end{array}$ & $\begin{array}{l}\text { Unable to } \\
\text { determine* }\end{array}$ \\
\hline \multicolumn{7}{|c|}{ Found following RRL (not validated) } \\
\hline Hypothetical & 233695 & $\mathrm{RRL}^{115-117}$ & QAGVYFSEEDR & WT & $\begin{array}{l}\text { LFQ } \\
\text { (HYTANE) }\end{array}$ & $\begin{array}{l}2 / 9 \mathrm{WT}, \\
0 / 9 \triangle \operatorname{asp} 5\end{array}$ \\
\hline Hypothetical & 297890 & $\mathrm{RRL}^{183-185}$ & (n)TTLASTLSLSR & WT & $\begin{array}{l}\text { LFQ } \\
\text { (HYTANE) }\end{array}$ & $\begin{array}{l}\text { 2/9 WT, } \\
\text { 0/9 } \triangle \text { asp } 5\end{array}$ \\
\hline $\begin{array}{l}\text { Hypothetical } \\
\text { (Zinc } \\
\text { Finger- } \\
\text { containing) }\end{array}$ & 248450 & $\mathrm{RRL}^{345-347}$ & (Ac)YAPGASVVESPVFGTPPSR & WT & $\begin{array}{l}\text { LFQ } \\
\text { (HYTANE) }\end{array}$ & $\begin{array}{l}\text { 1/9 WT, } \\
0 / 9 \triangle \operatorname{asp} 5\end{array}$ \\
\hline Hypothetical & 286530 & $\begin{array}{l}\mathrm{RRL}^{27-29} \\
\text { SP- } \\
\text { cleaved }^{b}\end{array}$ & $\begin{array}{l}\text { (n)MFAAAPLQSFSVTNKQFHPE } \\
\text { GLEAQAPRPHQGLDMR }\end{array}$ & Neither & $\begin{array}{l}\text { LFQ } \\
\text { (HYTANE) }\end{array}$ & $\begin{array}{l}\text { 4/9 WT, } \\
\text { 2/9 } \triangle \text { asp5 }\end{array}$ \\
\hline
\end{tabular}


bioRxiv preprint doi: https://doi.org/10.1101/271676; this version posted February 26, 2018. The copyright holder for this preprint (which was not certified by peer review) is the author/funder. All rights reserved. No reuse allowed without permission.

\begin{tabular}{|c|c|c|c|c|c|c|}
\hline \multicolumn{7}{|c|}{ Found following predicted signal peptide cleavage site } \\
\hline $\begin{array}{l}\text { WNG2 } \\
\text { (ROP34) }\end{array}$ & 240090 & $\begin{array}{l}\mathrm{AVA}^{62-64} \\
\text { (SP } \\
\text { cleaved) }\end{array}$ & $\begin{array}{l}\text { (n)AHAEHPEDSATNFLFSFAENS } \\
\text { LANREPPEDSAARPSSR }\end{array}$ & $\triangle a s p 5$ & $\begin{array}{l}\text { LFQ } \\
\text { (HYTANE) }\end{array}$ & $\begin{array}{l}\text { 0/9 WT, } \\
7 / 9 \triangle a s p 5\end{array}$ \\
\hline $\begin{array}{l}\text { WNG2 } \\
\text { (ROP34) }\end{array}$ & 240090 & $\begin{array}{l}\mathrm{AVA}^{61-64} \\
\text { (SP } \\
\text { cleaved) }\end{array}$ & $\begin{array}{l}\text { (fi)AHAEHPEDSATNFLFSFAE } \\
\text { NSLANR }\end{array}$ & Neither & $\begin{array}{l}\text { SILAC } \\
\text { (TAILS) }\end{array}$ & $\begin{array}{l}\text { WTH/KOL } \\
1.49 / 0.67 \\
\text { (not } \\
\text { significant) }\end{array}$ \\
\hline $\begin{array}{l}\text { WNG1 } \\
\text { (ROP35) }\end{array}$ & 304740 & $\begin{array}{l}\mathrm{AGA}^{68-70} \\
(\mathrm{SP} \\
\text { cleaved?) }^{\mathrm{C}}\end{array}$ & (Ac)TVAAPQVETGPLLSVR & WT & $\begin{array}{l}\text { Dimethyl } \\
\text { (TAILS) }\end{array}$ & $\begin{array}{l}\text { WT Light } \\
\text { DiMethyl } \\
5.31 \text { / } 0.18 \\
\text { WT Heavy } \\
\text { DiMethyl } \\
4.17 \text { / } 0.81\end{array}$ \\
\hline
\end{tabular}


838 Figure 1: Outline of experimental techniques for identification of N-terminal peptides

839 (A) Schematic of TEXEL protein processing within WT (left) and $\triangle a s p 5$ (right) parasites. (B)

840 Following protein extraction, exposed $\mathrm{N}$-termini (i.e. containing a free amino group, $-\mathrm{NH}_{2}$, black

841 sphere) were blocked following the addition of formaldehyde with a catalyst, resulting in

842 primary amine dimethylation. Dimethylation of the most N-terminal amine is depicted with a

843 blue star $\left(-\mathrm{N}\left(\mathrm{CH}_{3}\right)_{2}\right)$, while those on the R-chain of lysine residues are depicted with a grey star.

844 Naturally blocked N-termini, such as acetylated amines, did not undergo this reaction. The

845 blocked N-terminal peptides were then liberated from their respective proteins by digestion with

846 trypsin. Resulting tryptic peptides (containing an exposed $\mathrm{NH}_{2}$, black sphere) were then depleted

847 from the mixture either using the synthetic HPG-ALD polymer (TAILS) or using hexadecanal

848 (HYTANE), while the blocked peptides remained in solution; these were then desalted and run

849 on the mass spectrometer. (C) Quantitation techniques: SILAC samples ( $n=2$ reciprocally

850 labelled samples) were mixed prior to beginning the TAILS protocol, while Dimethyl samples

851 ( $\mathrm{n}=2$ reciprocally labelled samples) were mixed following heavy or light dimethylation of

852 primary amines on day 2 of this protocol. Label-free samples were processed separately $(\mathrm{n}=9$

853 replicates per group), and neo-N-termini depleted with the HYTANE protocol. WT: wild type,

$854 \triangle$ asp5: parasites lacking the enzyme ASP5, SP: signal peptide, $\mathrm{NH}_{2}$ : amine group, RRLxx:

855 TEXEL motif cleaved by ASP5, ASP5: aspartyl protease 5, Ac: acetylated N-terminus, R:

856 arginine, $\mathrm{K}$ : lysine, blue star: dimethylated $\left[\mathrm{N}\left(\mathrm{CH}_{2}\right)_{2}\right] \mathrm{N}$-terminal amino acid, red line: tryptic

857 cleavage site (after $\mathrm{R}$ ), black sphere: exposed $\mathrm{NH}_{2}$ group on the $\mathrm{N}$-terminus, grey star:

858 dimethylated R-chain of lysine. 
861 Figure 2: Comparison of shotgun-like preTAILS versus TAILS N-terminomics on

862 Toxoplasma peptides. (A) Greater than 7-fold enrichment for N-terminal modified peptides was

863 achieved in the SILAC samples when compared to the pre-TAILS analyses. (B) Unraveling the

864 features of blocked $\mathrm{N}$ termini. The vast majority of blocked $\mathrm{N}$-termini are naturally acetylated in

865 the Dimethyl and HYTANE samples or experimentally dimethylated during TAILS in the case

866 of the SILAC samples. (C) Overall, the HYTANE method had the lowest proportion of

867 unmodified peptides following TAILS enrichment compared with the Overall lab method which

868 uses the HPG-ALD polymer. (D) We identified 79 modified peptides common to all three

869 experiments, with the majority of peptides identified uniquely to the SILAC or HYTANE

870 experiments. (E) Log-Log plot representing the modified peptides with reciprocal protein

871 expression from the SILAC-TAILS experiments. Peptides were deemed significantly

872 differentially enriched in the WT sample if their $\log 2$ ratio was above 0.59 (equivalent to 1.5

873 fold). (F) Log-Log plot representing the modified peptides with reciprocal protein expression

874 from the heavy demethylation-TAILS experiments. Peptides were deemed significantly

875 differentially enriched in the WT sample if their Log2 ratio was above 0.59 (equivalent to 1.5

876 fold).

$879 \quad$ Figure 3; Methodology for validation of ASP5 substrates. (A) Schematic of endogenous

880 tagging, U6: U6 promoter, protospacer: 20-21 base pair sequence used to direct Cas9 to cut

881 within the parasite genome, gRNA: guide RNA, Cas9: enzyme that cuts DNA, SP: signal 
882 peptide, RRL: arginine; arginine; leucine, site of cleavage by ASP5, HA: haemagglutinin tag,

883 Ty: Ty tag, Red stop signal: endogenous stop codon or introduced stop codon/frameshift

884 mutation, ARL: mutation of first arginine to alanine. (B) Immunoblot of LCAT-HA 3

885 (TGGT1_272420) using the LI-COR Odyssey imager, $\alpha$ HA and $\alpha$ GAP45 antibodies used. Open

886 arrow heads indicate full length species, closed arrow heads indicate ASP5-cleaved species. (C)

887 IFA of LCAT-HA 3 expressing parasites, HA and GAP45 antibodies used (LCAT:

888 TGGT1_272420).

890 Figure 4: GRA43 is a novel ASP5 substrate. (A) Schematic of TGGT1_208370 (GRA43) with

891 a HA tag inserted after the signal peptide cleavage site, a TEXEL (RRL), transmembrane domain

892 (TM) and TY or HA tag inserted prior to the stop codon. (B) $\mathrm{i}$ - immunoblot of 3-8 \% Tris-

893 Acetate (TA) gel using $\alpha \mathrm{HA}$ antibodies (N-terminal fragment), ii - using $\alpha \mathrm{Ty}$ antibodies (C-

894 terminal fragment). Open arrow heads indicate full length species, closed arrow heads indicate

895 ASP5-cleaved species. (C) Extracellular IFA. (D) Immunoblot using the LI-COR Odyssey

896 imager. (E) IFA at 3 hours post invasion. (F) IFA at 24 hours post invasion of replicating

897 parasites.

899 Figure 5: WNG1 and WNG2 are ASP5 substrates that localise to the host-parasite

900 boundary. (A) Schematic of WNG1. (B) Immunoblot using the LI-COR Odyssey imager. Open

901 arrow heads indicate full length species, closed arrow heads indicate ASP5-cleaved species. (C)

902 IFAs at 24 hours post invasion with rhoptry markers $\alpha$ ROP2/3/4 or the dense granule marker

903 MAF1. (D) Schematic of WNG2. (E) Immunoblot using the LI-COR Odyssey imager. Open

904 arrow heads indicate full length species, closed arrow heads indicate ASP5-cleaved species. (F) 
905 IFAs at 24 hours post invasion with rhoptry markers $\alpha$ ROP2/3/4 or the dense granule marker

906 MAF1.

907

908 Figure 6: GRA44 is matured by ASP5 and localises to the PVM.

909 (A) Schematic of GRA44 based off the TGGT1_228170 sequence. (B) Immunoblot using the LI-

910 COR Odyssey imager, $\alpha \mathrm{HA}$ and $\alpha \mathrm{GAP} 45$ antibodies used. Open arrow heads indicate expected

911 size of full length species, closed arrow heads indicate predicted ASP5-cleaved species. (C)

912 Plaque assay at 9 days depicting plaque sizes for WT (RH $\Delta k u 80 \Delta h x), \Delta g r a 44$

913 (RH $\Delta k u 80 \Delta h x \Delta g r a 44)$ and $\Delta a s p 5$ (RH $\Delta k u 80 \Delta h x \Delta a s p 5)$. (D) IFA of an extracellular tachyzoite

914 depicting WT GRA44-HA (green) and the dense granule marker GRA1 (magenta). (E)

915 Intracellular IFAs of WT- and $\triangle a s p 5-G R A 44-H A$ parasites with the IMC marker IMC1 (E-i) and

916 the dense granule marker MAF1 (E-ii). (F) Immunoblot using the LI-COR Odyssey imager,

$917 \alpha \mathrm{HA}$ and $\alpha \mathrm{GAP} 45$ antibodies used. Open arrow heads indicate the predicted full-length species,

918 closed arrow heads indicate predicted ASP5-cleaved species. (G) IFA of WT intracellular

919 parasites expressing GRA45-HA (green) with GAP45 (upper panel) and MAF1 (lower panel).

920

$921 \quad$ Figure 7: WNG2 and GRA43 are important for acute virulence.

922 (A-C) Immunoblots confirming genetic disruption of WNG1 (A), WNG2 (B) and GRA43 (C) in

923 Pru $\triangle k u 80$ parasites. (D-I) Kaplan-Meier survival curves of C57BL/6 mice with strains as

924 indicated (upper panels) and pooled bodyweight (lower panels). Survival curve comparisons

925 were assessed using the Log-Rank (Mantel-Cox) test and significance assessed following

926 correction for the Bonferroni threshold when performing multiple comparisons. (D) Six

927 C57BL/6 mice were infected with $2000 \mathrm{WT}(\operatorname{Pru} \triangle k u 80)$ or $\Delta$ asp5 (Pru $\triangle k u 80 \Delta a s p 5)$ tachyzoites 
928 via intraperitoneal (IP) injection. $p=0.0012$. (E) C57BL/6 mice $(n=3)$ were infected via IP

929 injection with $5 * 10^{3}$ or $5 * 10^{4} \mathrm{WT}(\operatorname{Pru} \Delta k u 80)$ or $\Delta a s p 5(\operatorname{Pru} \Delta k u 80 \Delta a s p 5)$ tachyzoites. $\mathrm{p}=$

9300.0295 for both comparisons. $(\mathrm{F})$ Mice $(\mathrm{n}=6)$ were infected via IP injection with $10^{3}$ tachyzoites

931 of WT (Pru $\Delta k u 80), \Delta w n g 2(\operatorname{Pru} \Delta k u 80 \Delta w n g 2)$ and $\Delta g r a 43$ (Pru $\Delta k u 80 \Delta g r a 43)$ backgrounds.

932 Significance: WT vs $\Delta w n g 2, \mathrm{p}=0.0012$. WT vs $\Delta$ gra43, $\mathrm{p}=0.0023$. (G) Infection via IP

933 injection with Pru $\triangle k u 80$ WNG1-HA (WNG1 WT), Pru $\triangle k u 80$ WNG1 $1_{\mathrm{ARL}}-\mathrm{HA}(\mathrm{WNG} 1 \mathrm{ARL})$ and

934 Pru $\Delta k u 80 \Delta w n g l(\Delta w n g 1) . \mathrm{n}=5,6$ and 6 respectively. $(\mathrm{H})$ Infection via IP injection $(\mathrm{n}=6)$ with

935 Pru $\triangle k u 80$ WNG2-HA (WNG2 WT), Pru $\Delta k u 80$ WNG2 $2_{\mathrm{ARL}}-\mathrm{HA}\left(\mathrm{WNG} 2_{\mathrm{ARL}}\right)$ and Pru $\Delta k u 80 \Delta w n g 2$

936 ( $\Delta w n g 2)$. Statistics: WNG2 WT vs $\Delta w n g 2, \mathrm{p}=0.0012 . \mathrm{WNG} 2_{\mathrm{ARL}}$ vs $\Delta w n g 2, \mathrm{p}=0.0029$. (I)

937 Infection via IP injection $(\mathrm{n}=6)$ with Pru $\triangle k u 80$ GRA43-HA (GRA43 WT), Pru $\triangle k u 80$

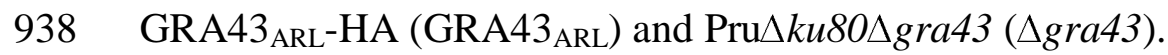




\section{Coffey et al. Figure 1}

A

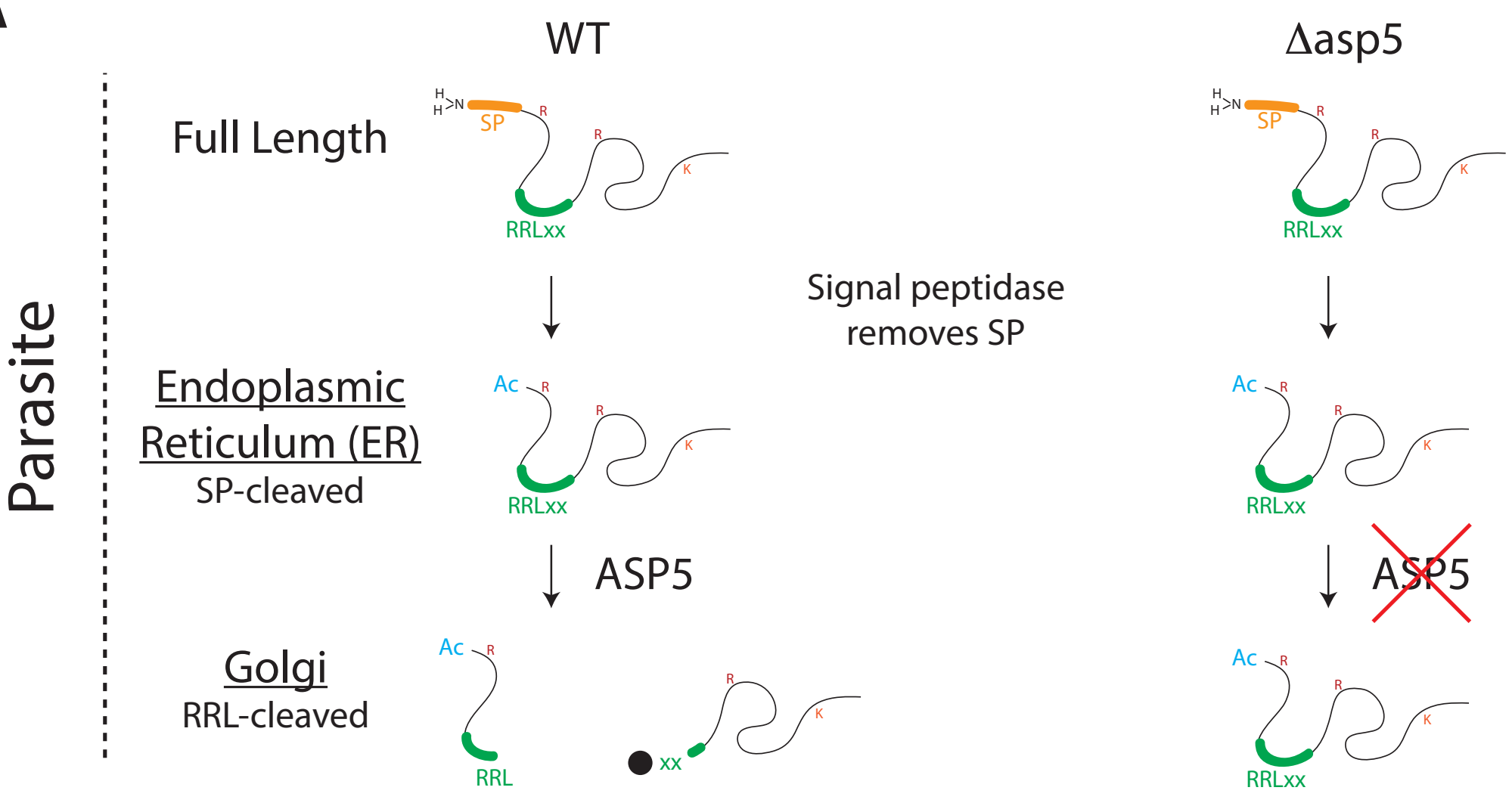

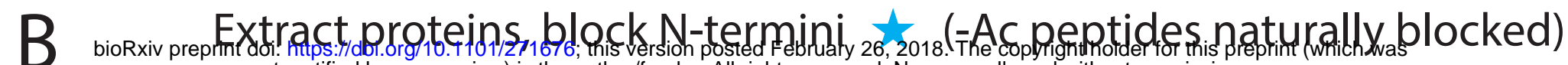

not certified by peer review) is the author/funder. All rights reserved. No reuse allowed without permission.

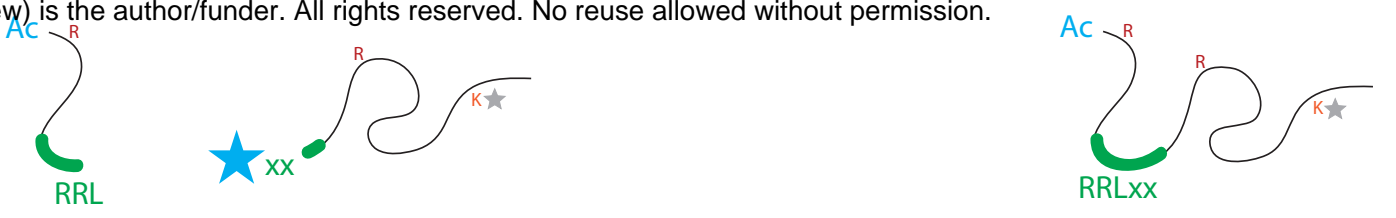

Digest with trypsin. This exposes free amine group $\left({ }_{H>N}^{H}=\mathbf{\bullet}\right.$

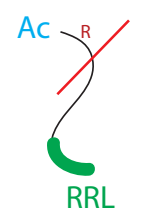

$\sum_{R R L}^{R}$
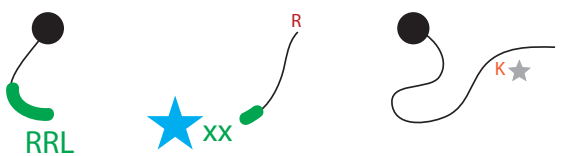

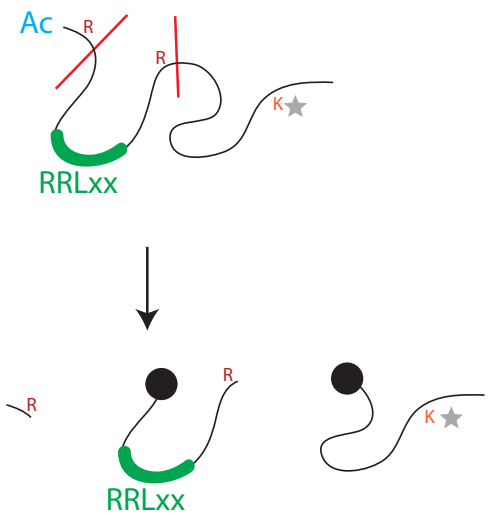

RRLXX

\section{Deplete tryptic peptides with exposed amine}

WT

$A c \overbrace{}^{R}$

May be present at low levels

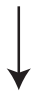

Potentially degraded if short
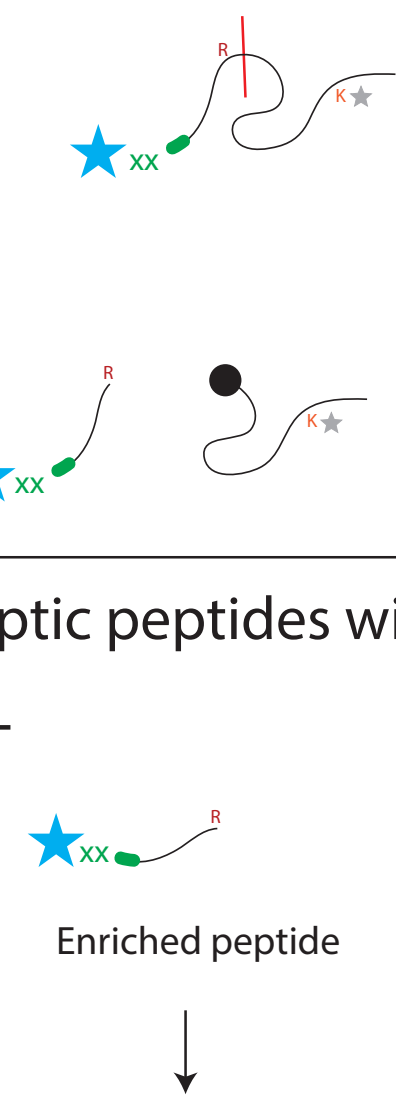

New N-term of protein

May be $\mathrm{N}$-acetylated or dimethylated
$\Delta$ asp5

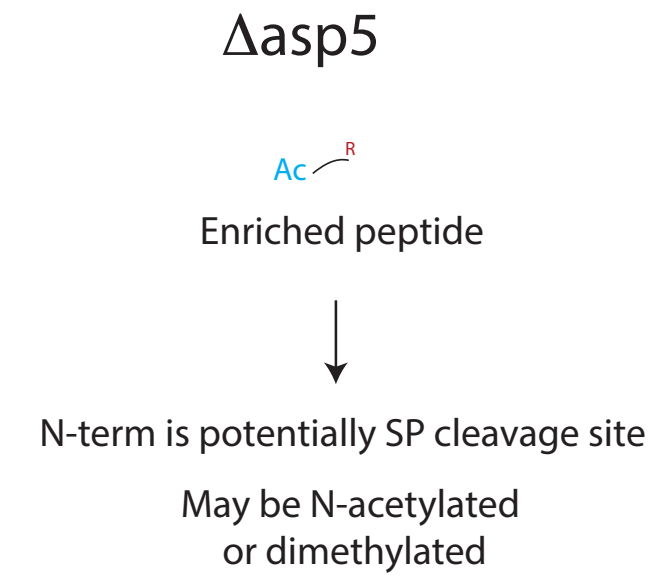

or dimethylated

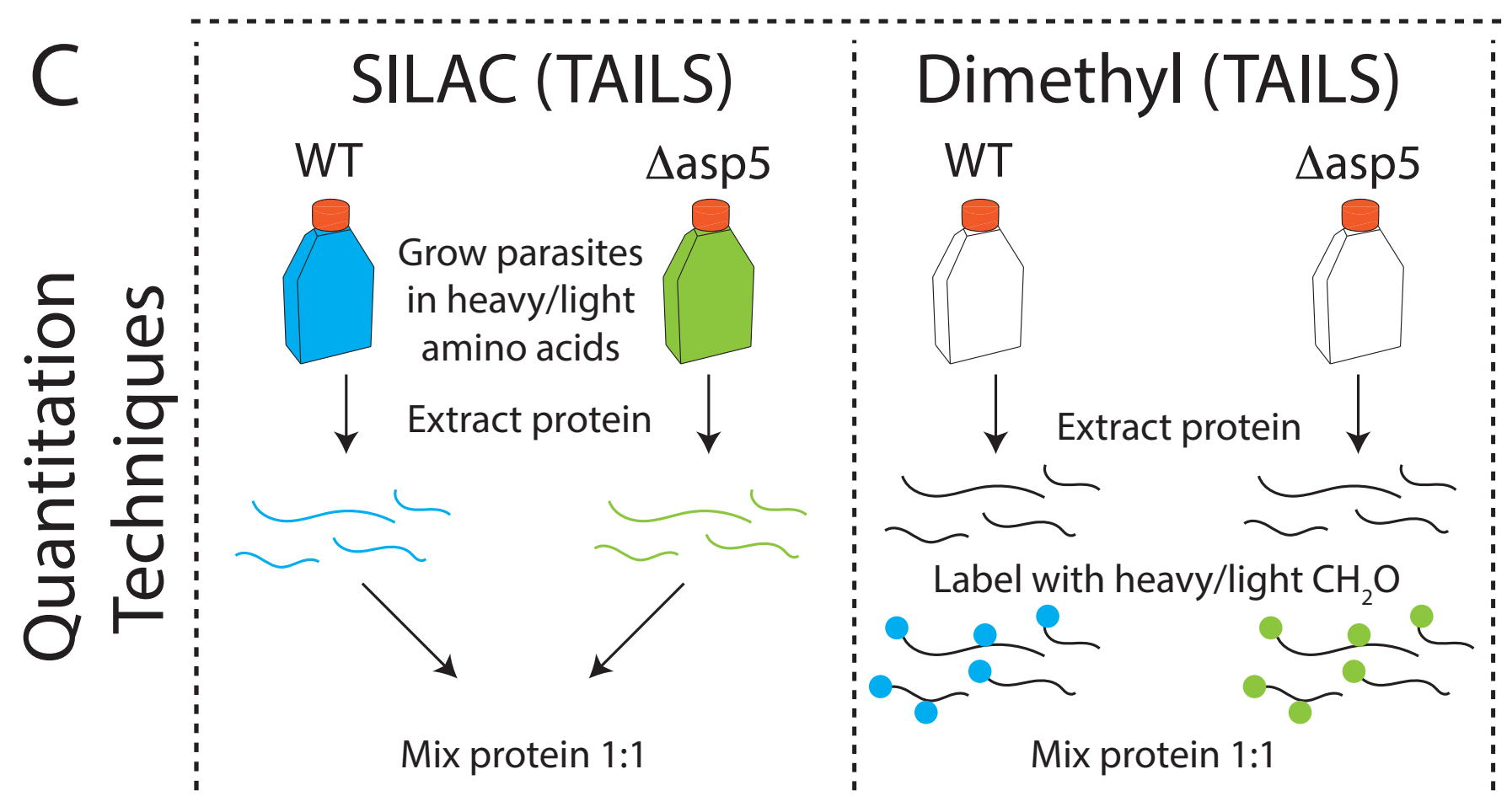

Label-free (HYTANE)

WT

$\Delta$ asp5

$P$
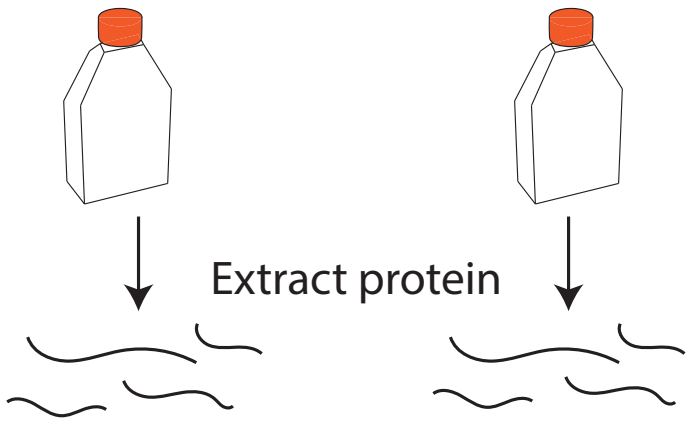

Process WT and $\Delta$ asp5 samples separately

Assess whether the peptide was detected in WT or $\Delta$ asp5 samples 


\section{Coffey et al. Figure 2}

A

B
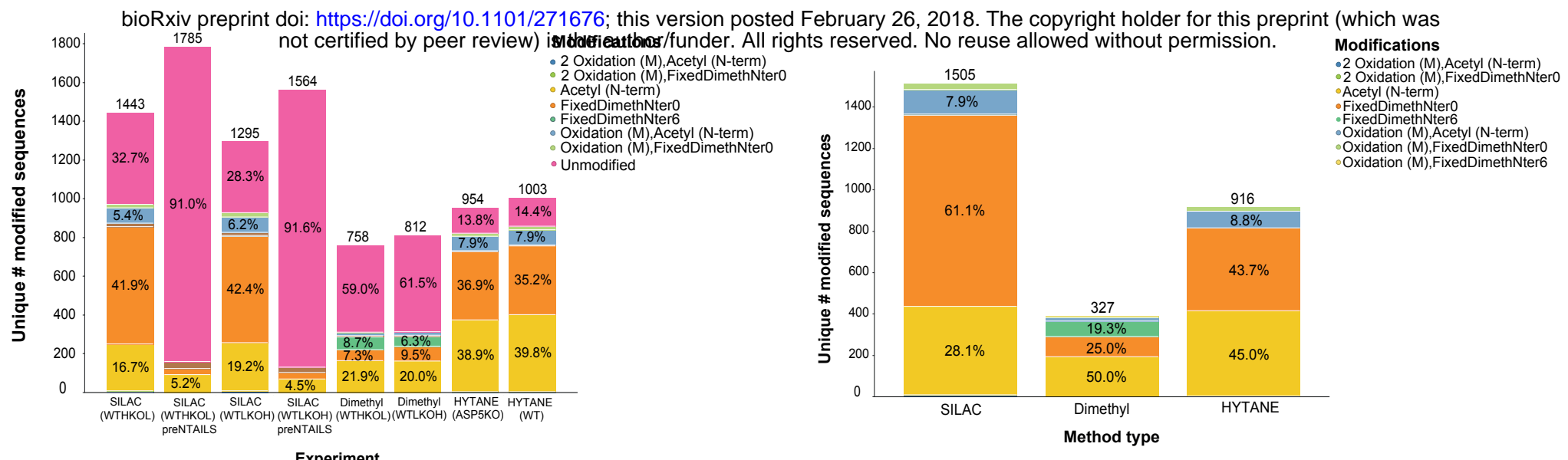

C

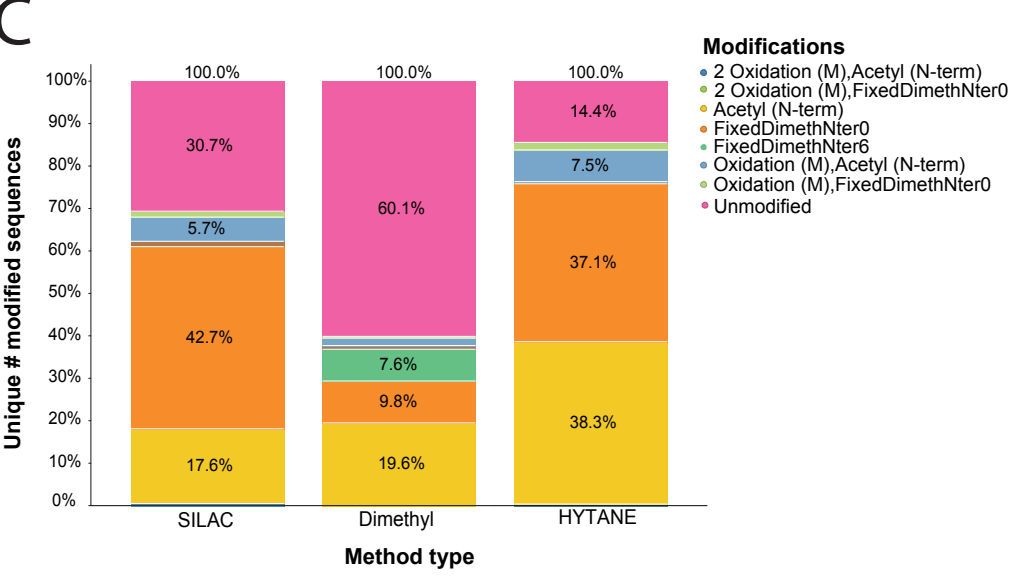

\section{D}

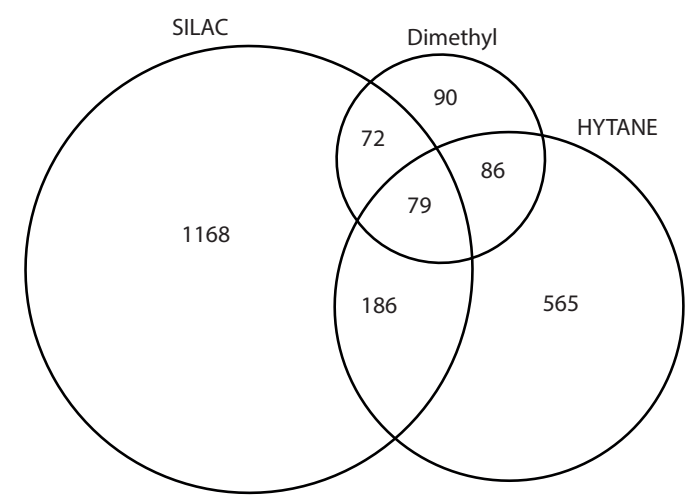

E

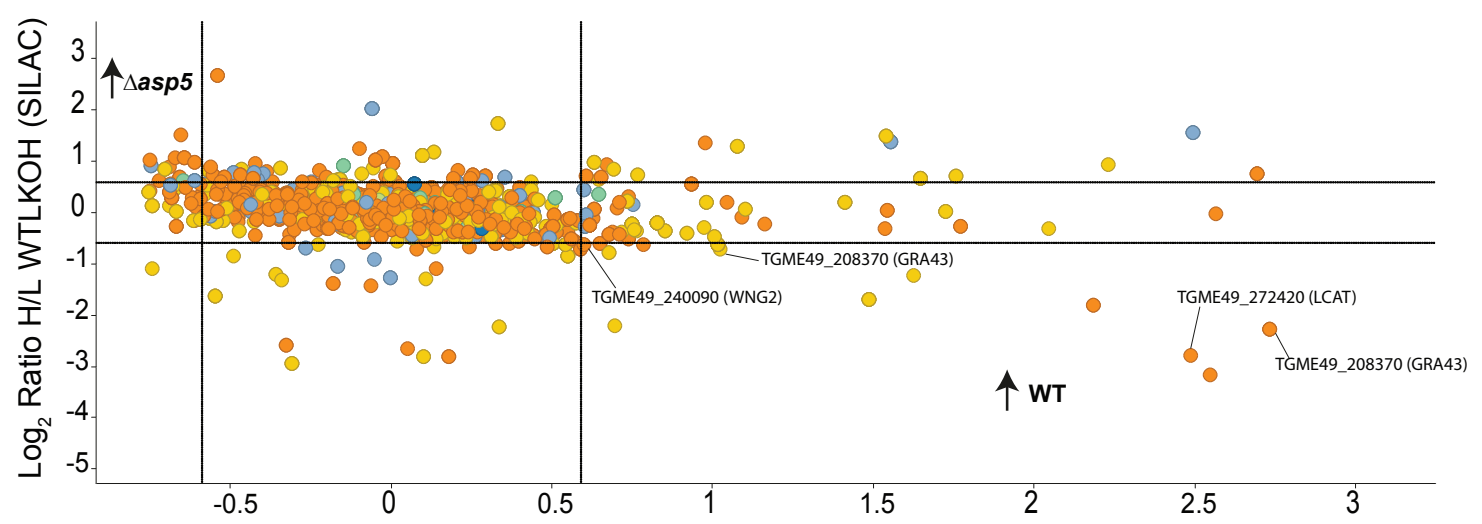

\section{Modifications}

- 2 Oxidation (M);Acetyl (N-term)

2 Oxidation (M); FixedDimethNterO - Acetyl (N-term)

- FixedDimethNterO

- Oxidation (M):Acetyl (N-term)

- Oxidation (M);FixedDimethNterO

$\log _{2}$ Ratio H/L normalized WTHKOL (SILAC)

F

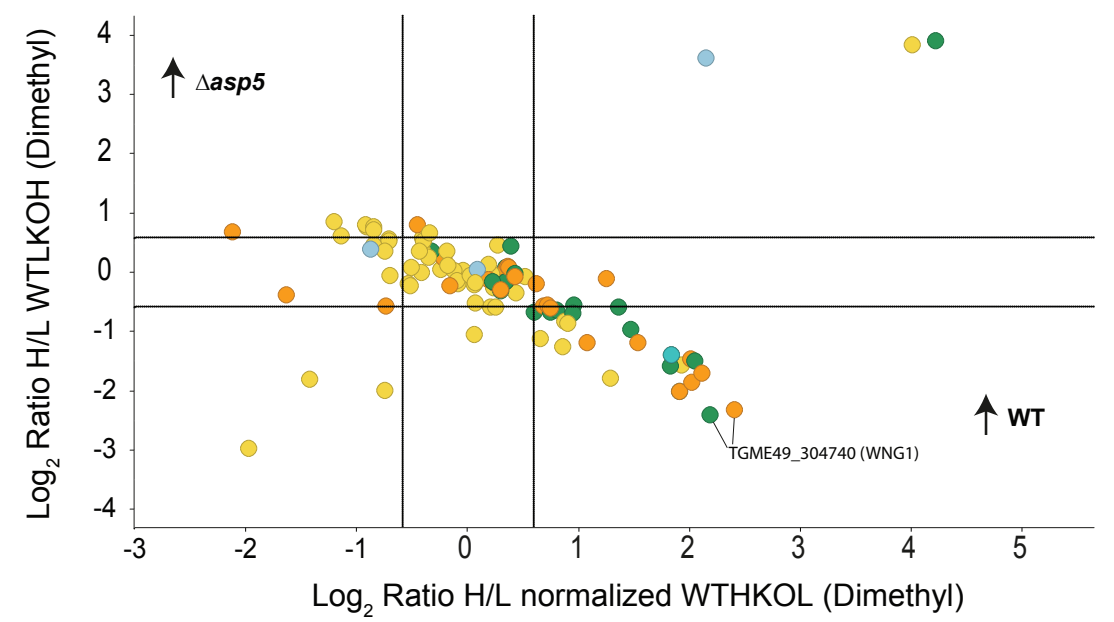

Modifications

Acetyl (N-term)

- Oxidation (M);Acetyl (N-term)

- Oxidation (M);FixedDimethNterO

- Oxidation (M);FixedDimethNter6

- FixedDimethNter0

- FixedDimethNter6 
Coffey et al. Figure 3

A
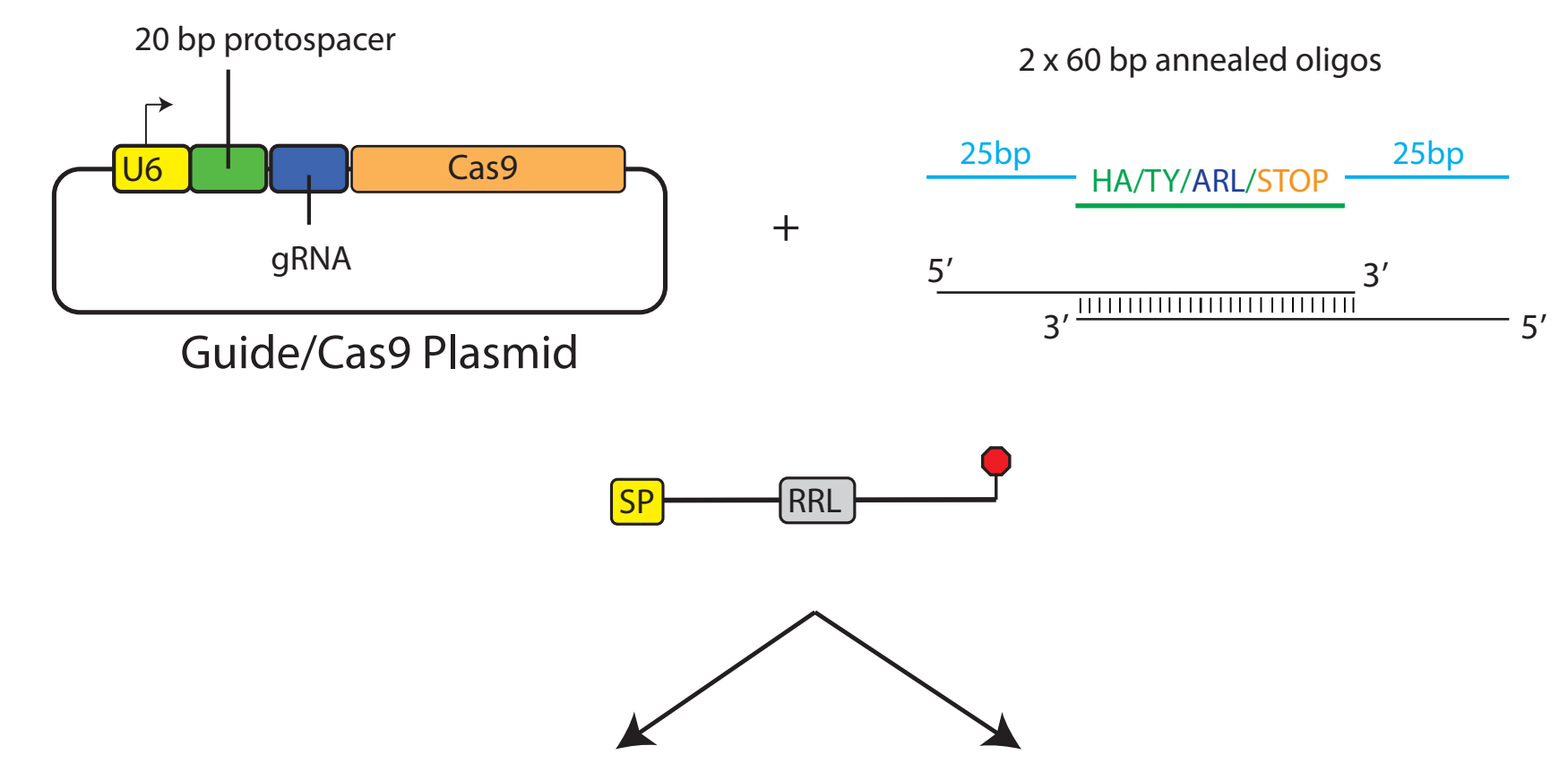

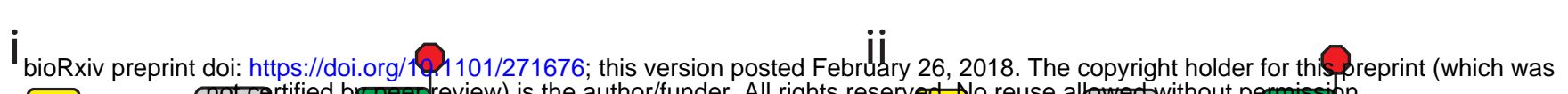

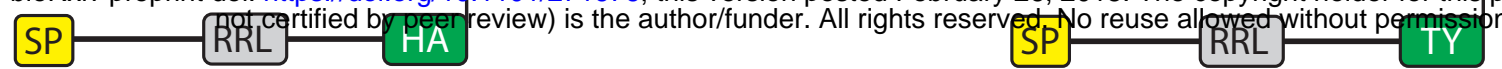

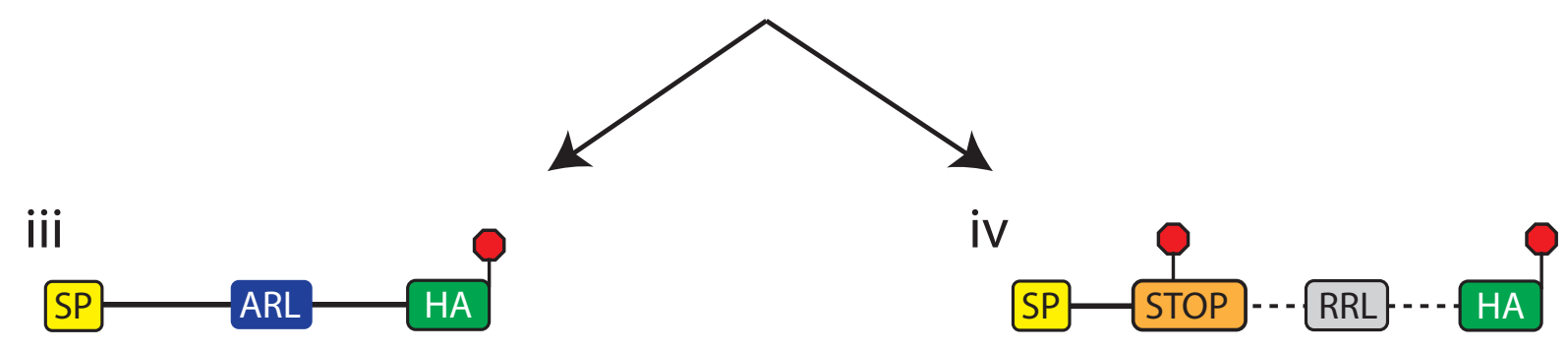

B

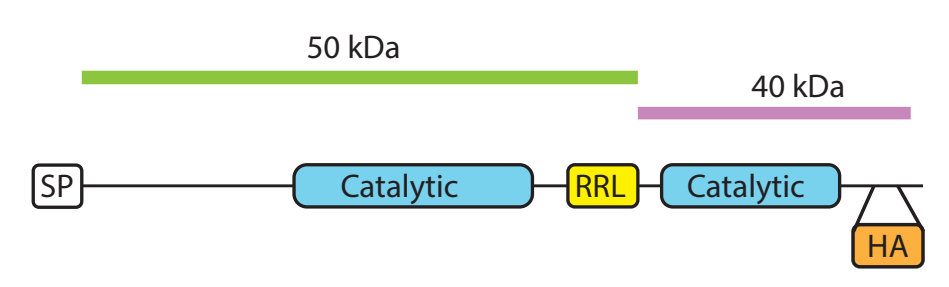

C

\section{LCAT-HA $/$ / GAP45 / DAPI}
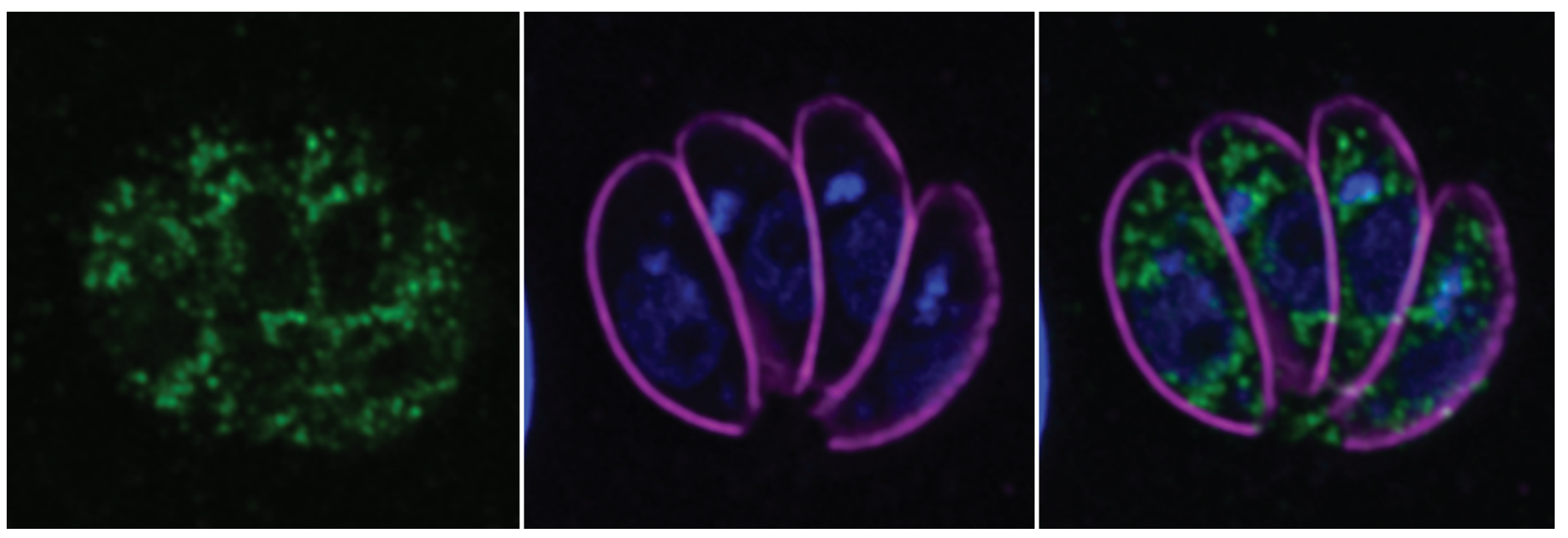


\section{Coffey et al. Figure 5}

A

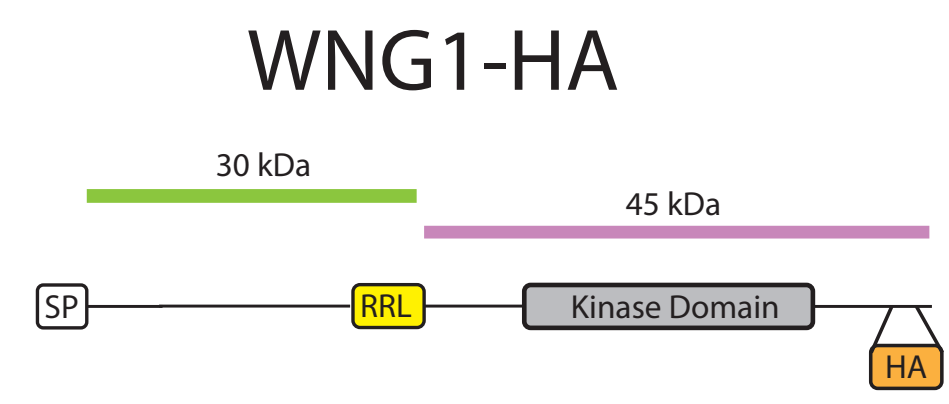

B

D

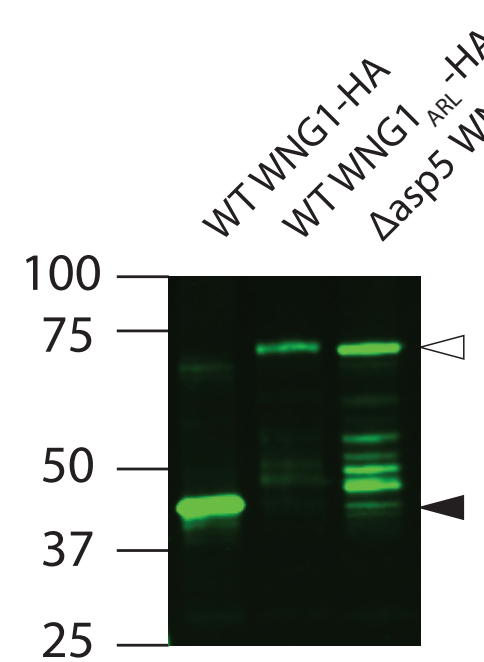

bioRxiv preprint doi: https://dol.org $/$ / $0.1101 / 271676$; this version posted February 26, 2018. The copyright holder 50 no

37

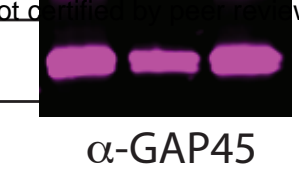

WNG2-HA

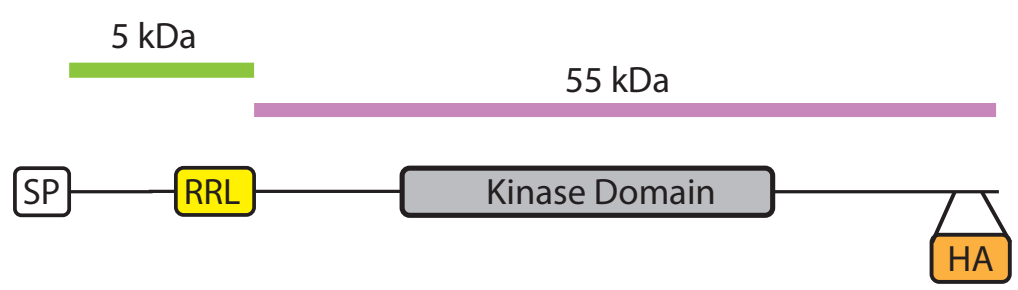

E

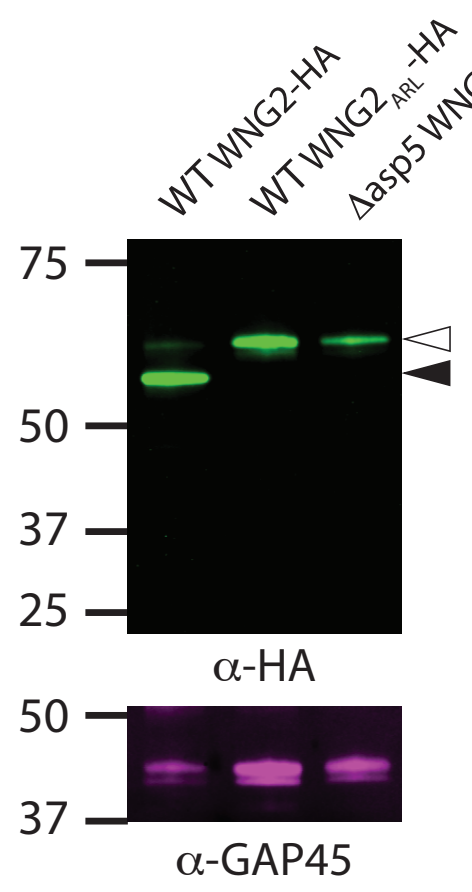

$\mathrm{Ci}$

WNG1-HA (rabbit) / ROP2/3/4 / DAPI

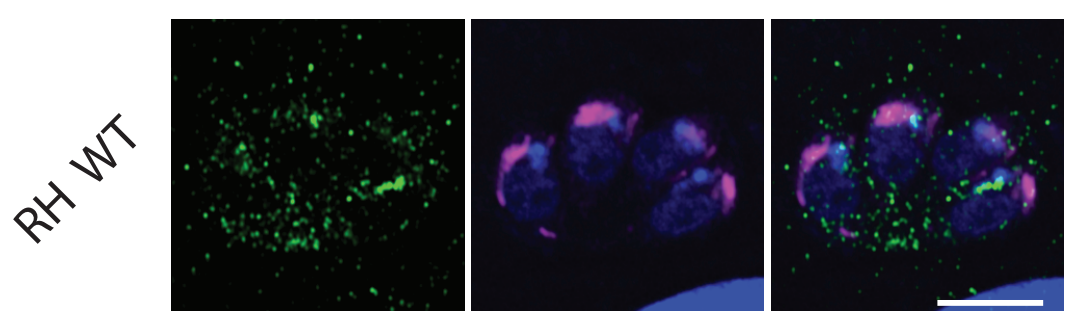

Cii

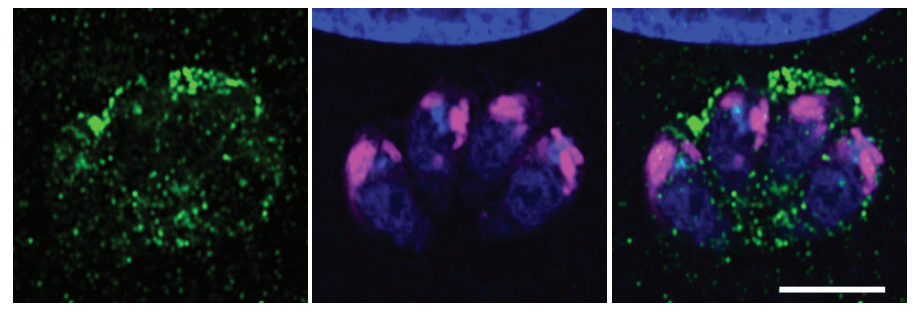

WNG1-HA (rat) / MAF1 / DAPI

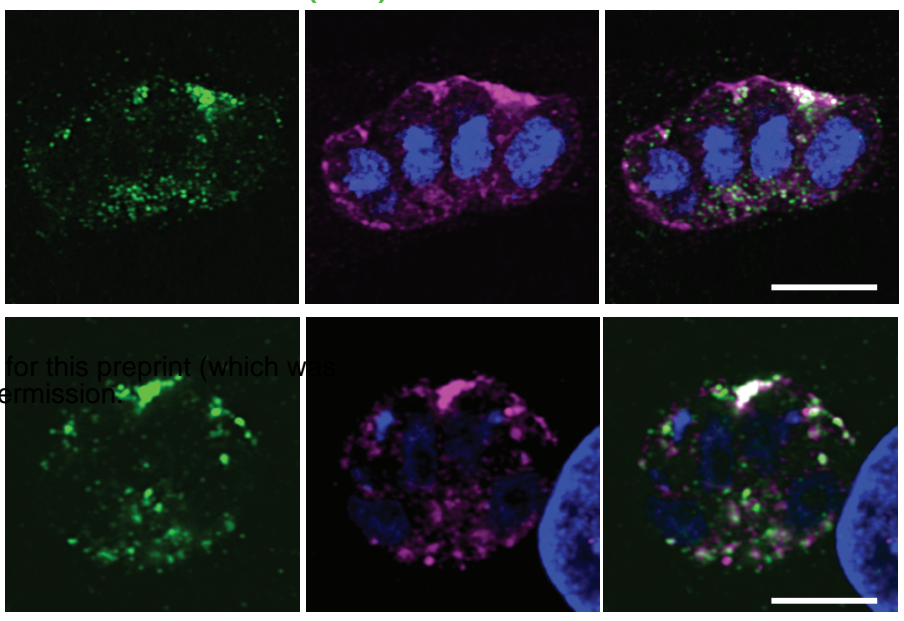

$\mathrm{Fi}$

WNG2-HA (rabbit) / ROP2/3/4 / DAPI
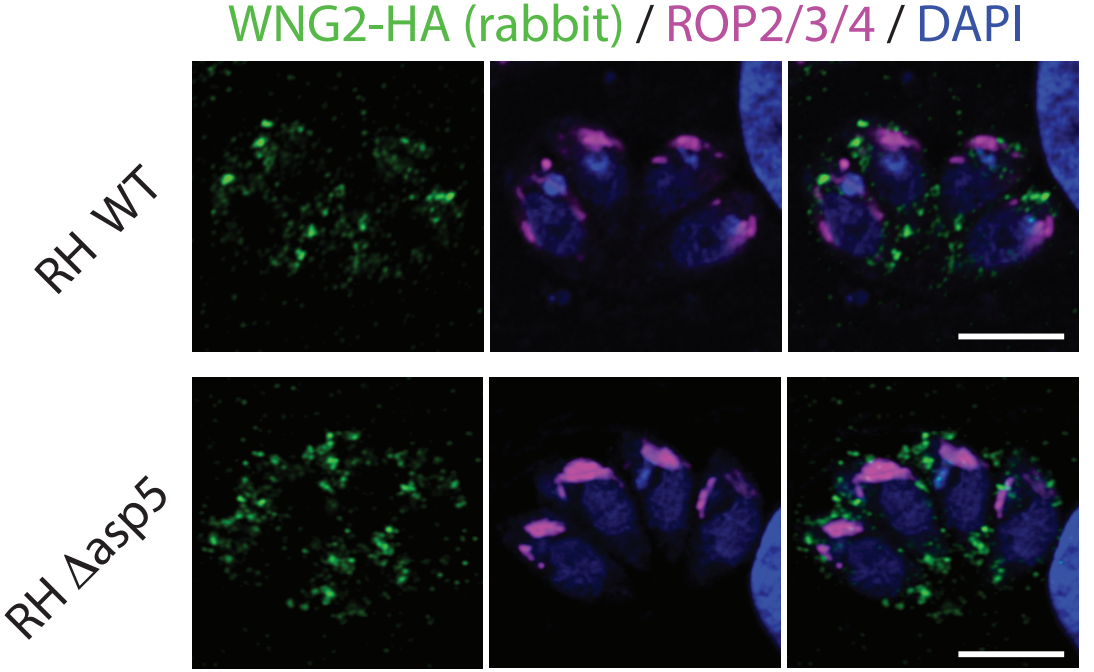

Fii

WNG2-HA (rat) / MAF1 / DAPI
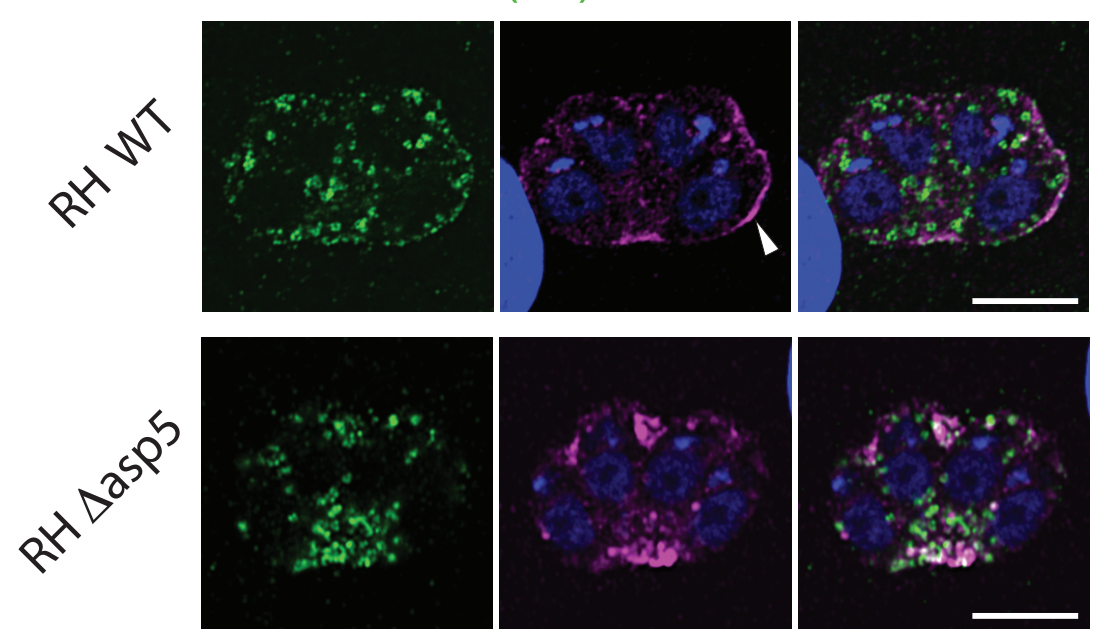
Coffey et al. Figure 6

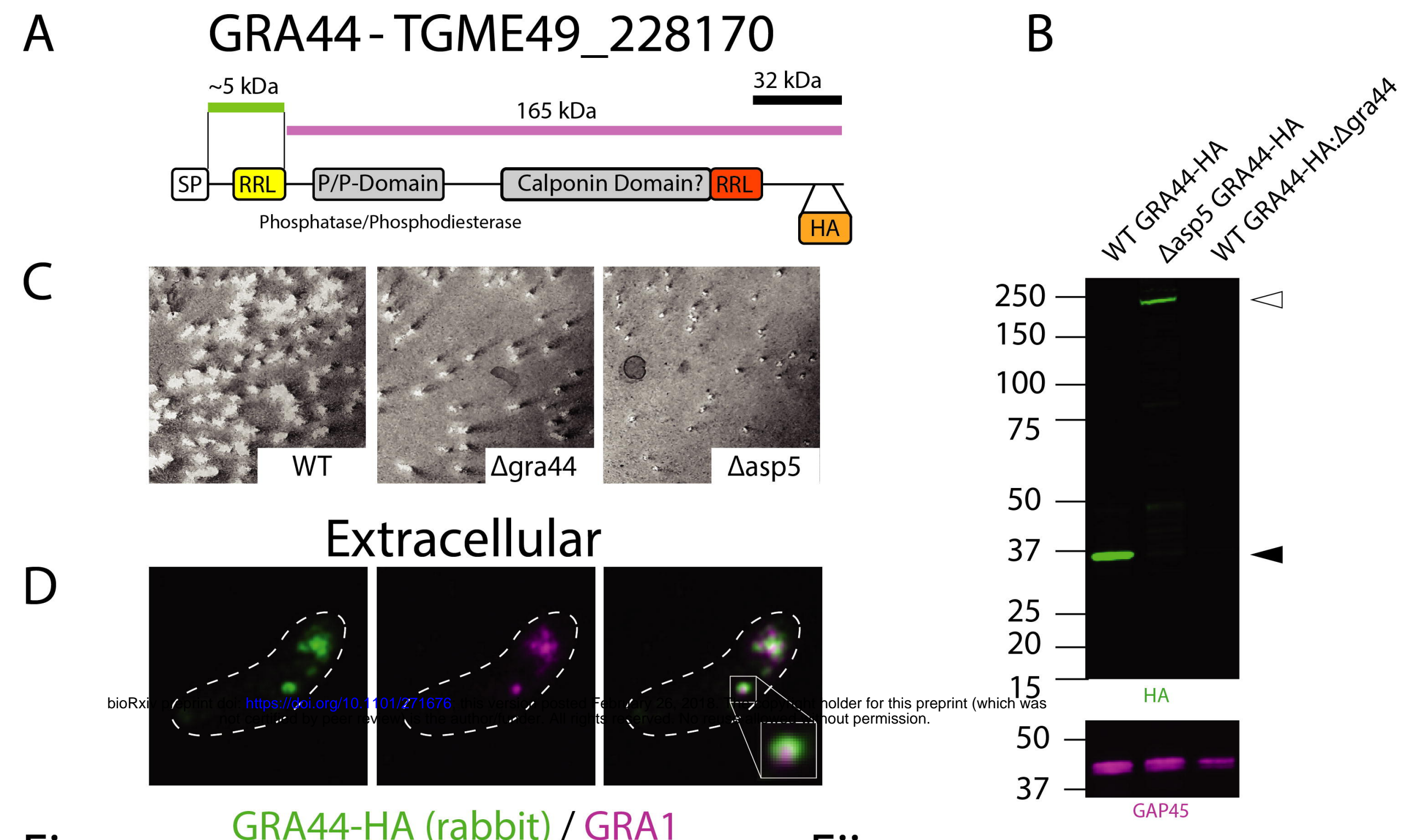

$\mathrm{Ei}$

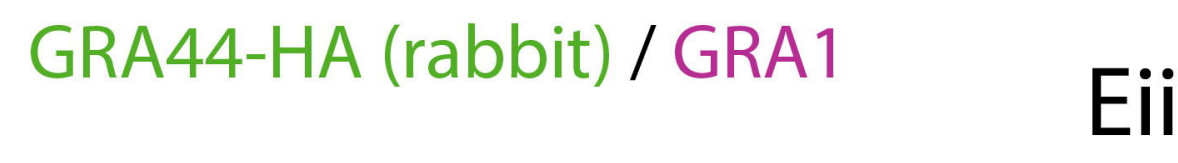

GRA44-HA (rabbit) / IMC1 / DAPI
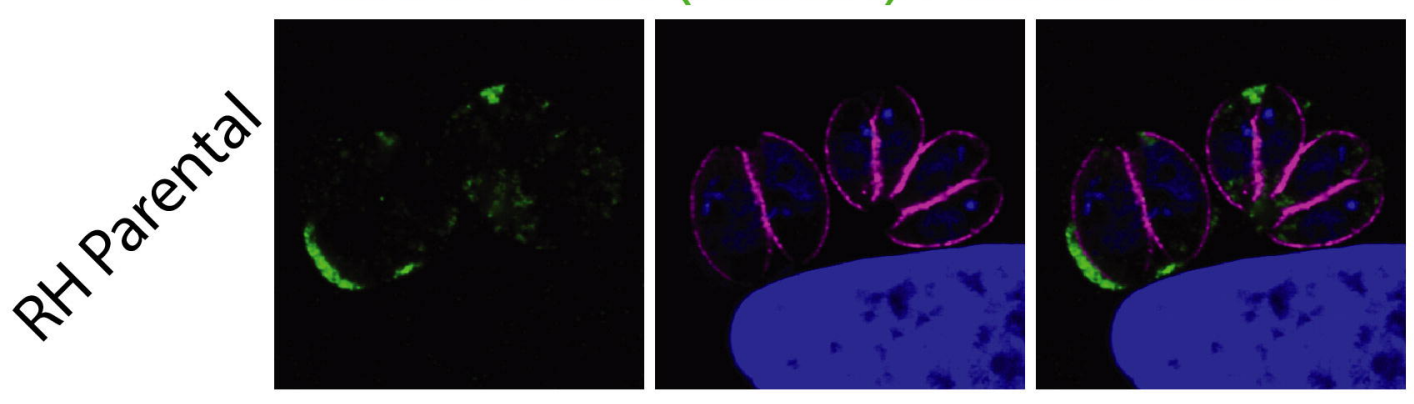

GRA44-HA (rat) / MAF1 / DAPI
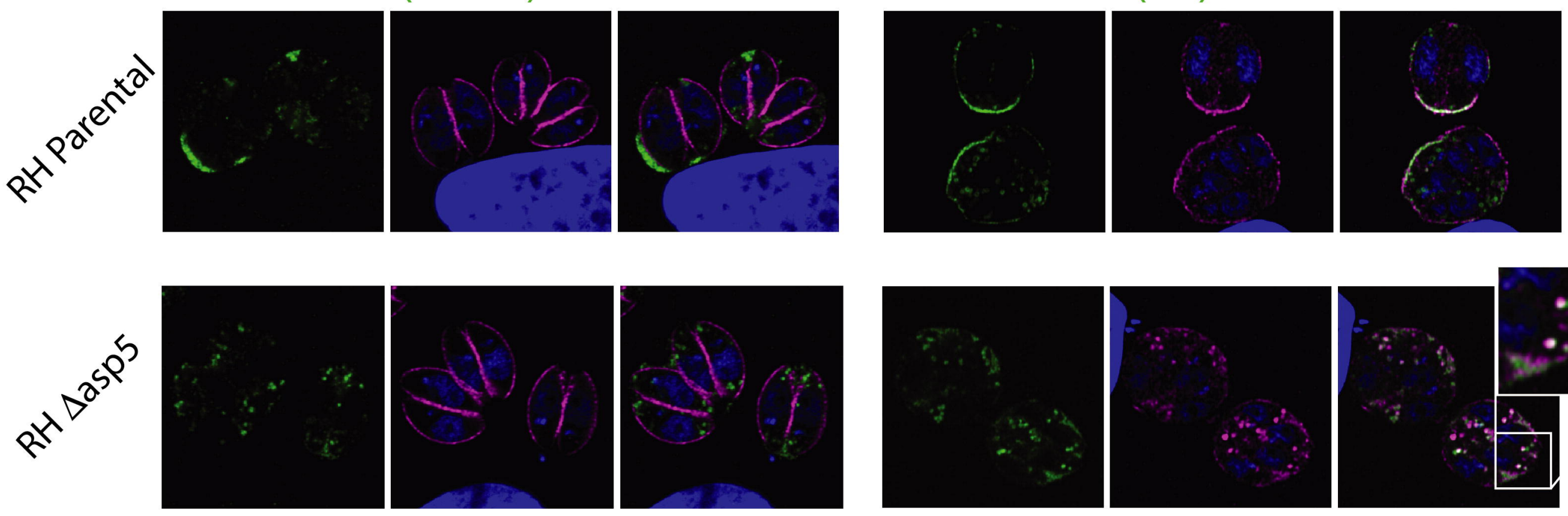

GRA45-TGME49_316250 G

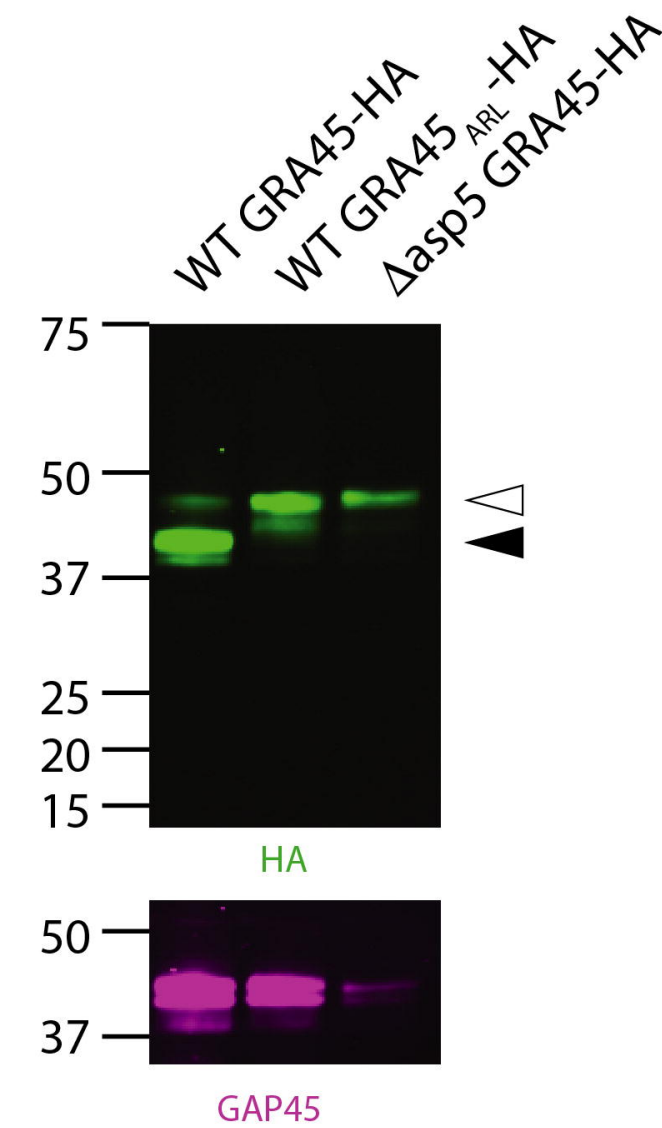

GRA45-HA (rat) / GAP45 / DAPI
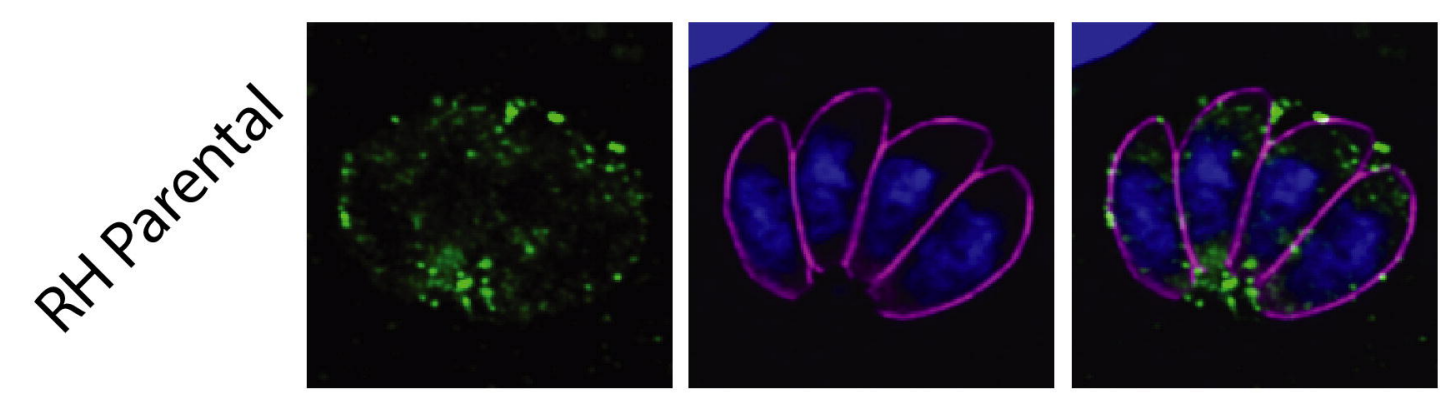

GRA45-HA (rat) / MAF1 / DAPI
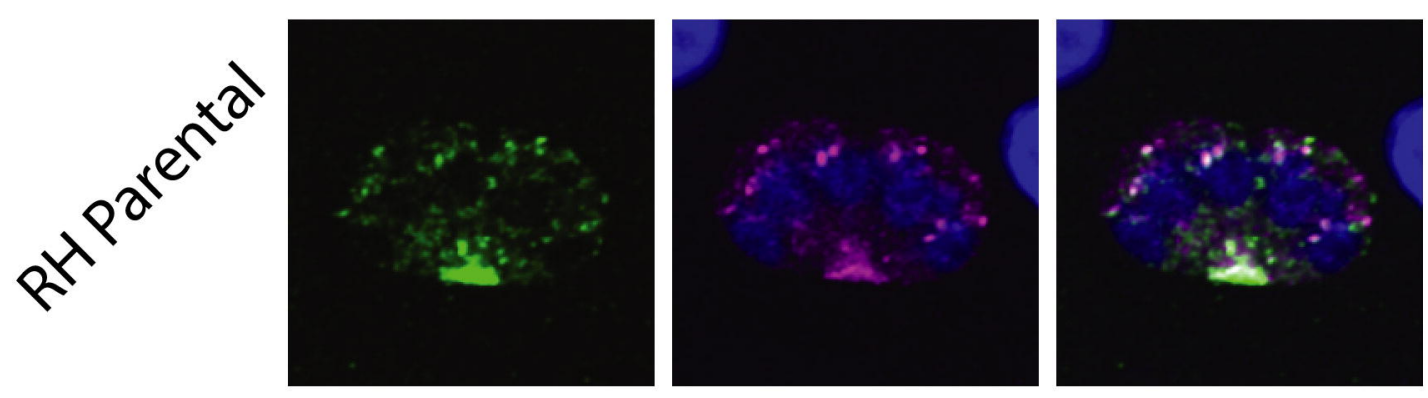


\section{Coffey et al. Figure 7}

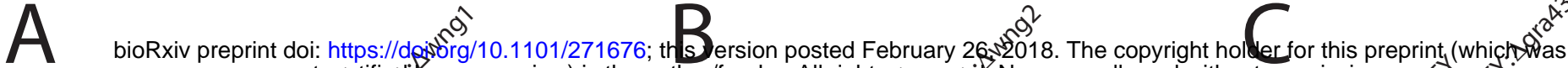
not atififis peer review) is the author/funder. All rights

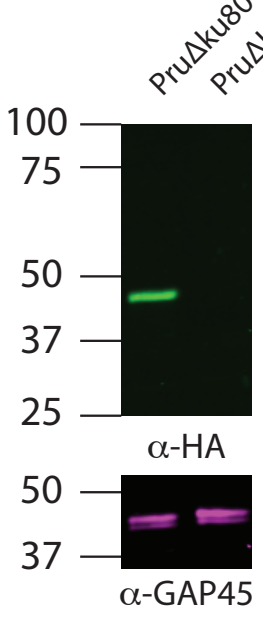

D

WT vs $\Delta$ asp5 (2000 dose)

Survival

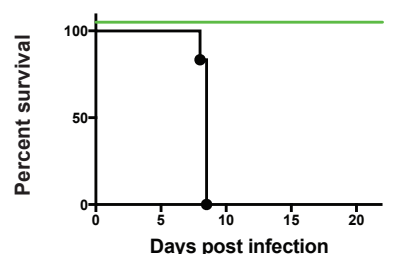

Bodyweight

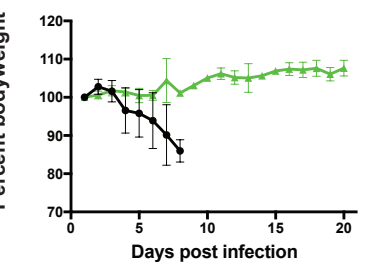

$G$

WNG1

Survival

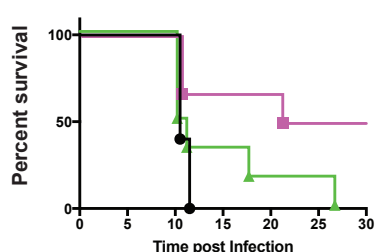

Bodyweight

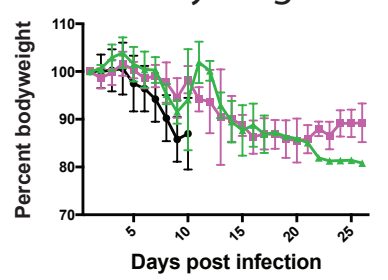

WT vs $\Delta$ asp5 $(5000,50000)$

Survival

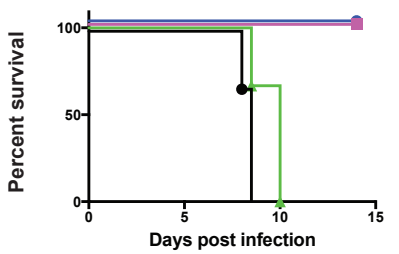

Bodyweight

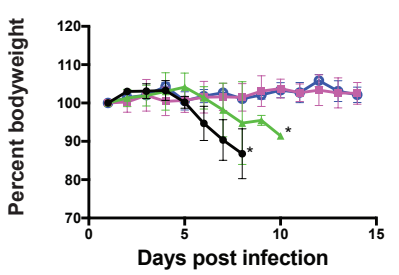

$\mathrm{H}$

WNG2

Survival

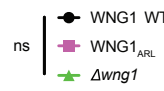

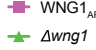

- WNG1 WT

-WNG1

- $\Delta w n g 1$

Bodyweight

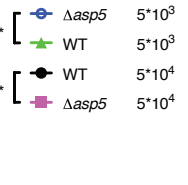

F

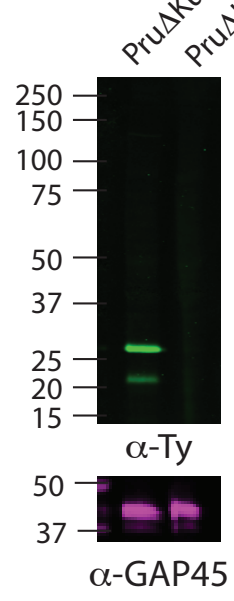

WT vs $\Delta w n g 2$ vs $\Delta$ gra43 (1000)

Survival

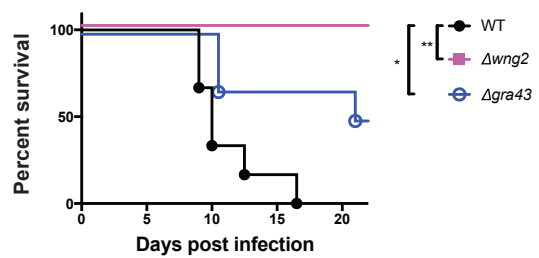

Bodyweight
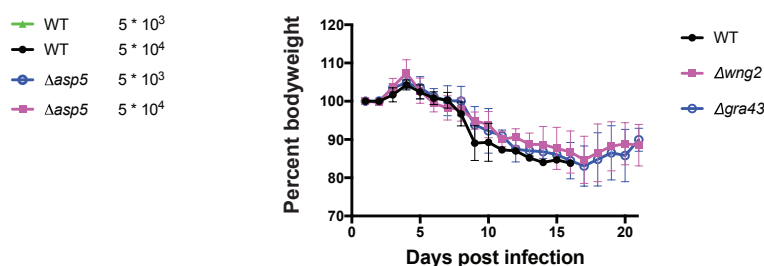

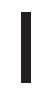

\section{GRA43}

Survival
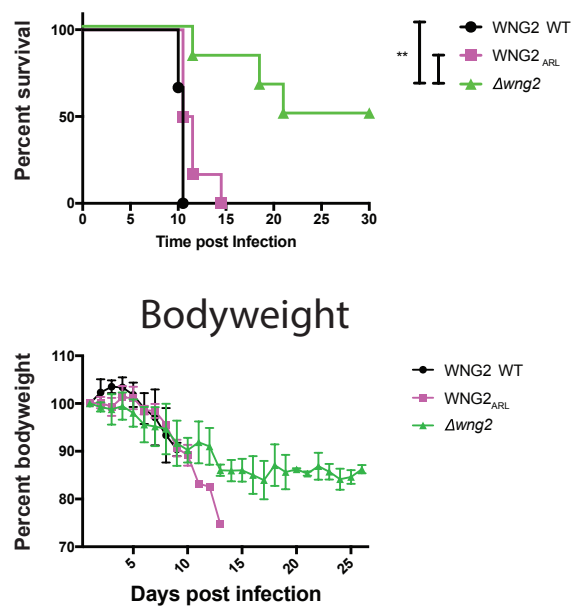

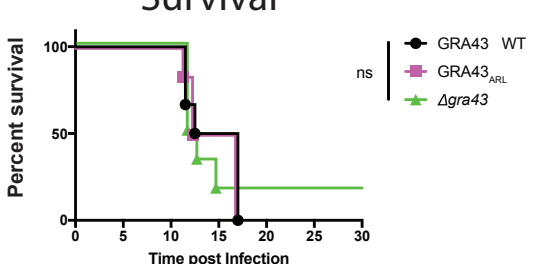

Bodyweight

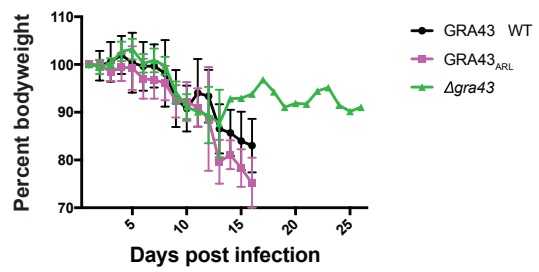

